\title{
The Dynamic (In)efficiency of Monetary Policy by Committee
}

\author{
Alessandro Riboni and Francisco J. Ruge-Murcia*
}

December 2007

\begin{abstract}
This paper develops a model where the value of the monetary policy instrument is selected by a heterogenous committee engaged in a dynamic voting game. Committee members differ in their institutional power and, in certain states of nature, they also differ in their preferred instrument value. Preference heterogeneity and concern for the future interact to generate decisions that are dynamically inefficient and inertial around the previously-agreed instrument value. This model endogenously generates autocorrelation in the policy variable and helps explain the empirical observation that the distribution of actual interest rate changes has a mode of zero.
\end{abstract}

JEL Classification: E4, E5, D7

Key Words: status-quo bias, policy conservatism, policy inertia, gridlock interval, dynamic voting, interest-rate smoothing.

*Both authors: Département de sciences économiques, Université de Montréal. We thank two anonymous referees and participants in the conference on New Developments in the Analysis of Monetary Policy and Institutions at Tel Aviv University (December, 2005), the Meetings of the European Economic Association (Vienna, 2006), and seminars at the Board of Governors and the Bank of Canada for helpful comments. This research received the financial support of the Social Sciences and Humanities Research Council of Canada. Correspondence: Francisco J. Ruge-Murcia, Département de sciences économiques, Université de Montréal, C.P. 6128, succursale Centre-ville, Montréal (Québec) H3C 3J7, Canada. 


\section{Introduction}

This paper studies the dynamic implications of monetary policy making by committee. The subject matter is important because, in many countries, monetary policy decisions are made by committees, rather than by one individual alone. For example, Fry et al. (2000) report that in a sample of 88 central banks, 79 use some form of committee structure to formulate monetary policy.

In particular, this paper focuses on a two-person committee where heterogenous agents must select the value of the policy instrument (say, the nominal interest rate) but face exogenous uncertainty regarding their preferred policies in the future. The committee members differ in two ways. First, agents have different state-dependent preferences over policy. There are states of nature where agents do not agree in their preferred instrument value, and states where they agree. Second, agents differ in their institutional role. More concretely, one agent, the chairman or agenda setter, makes a take-it-or-leave-it proposal to the other agent in every period. This assumption captures the idea that chairmen usually have more power and influence than their peers as a result of additional legal responsibilities, statutory prerogatives, or prestige. The identity of the chairman and the composition of the committee are assumed to be fixed over time. An important and plausible feature of the voting game is that the instrument value decided in the previous meeting is the default option in case the proposal is rejected in the current meeting. Hence, the current status quo is a state variable. ${ }^{1}$

In this setup, the first-best policy (that is, the state-contingent program that a benevolent social planner would choose) prescribes the policy preferred by both agents in states of agreement and optimal risk-sharing in states of disagreement. However, the politico-economic equilibrium cannot implement the first-best policy in the absence of a commitment technology. Instead, the politico-economic equilibrium features inefficient policy choices in all states of nature. First, in states of agreement, committee members do not select their common preferred policy. The reason is that forward-looking policy makers realize that current decisions affect future voting outcomes by changing the default option in the next meeting. Hence, in choosing the current policy, committee members trade-off the benefit of selecting their preferred policy for this period and the cost of affecting their bargaining power in future states of disagreement. Simulations show that this form of "political failure"

\footnotetext{
${ }^{1}$ The empirical relevance of this assumption in many policy decisions is discussed in Tsebelis (2002, p. 8). The theoretical literature on bargaining with evolving defaults is scant. Among the few contributions, see Baron (1996), Baron and Herron (2003), Bullard and Waller (2004), Bernheim et al. (2006) and Fong (2006). To the best of our knowledge, this paper is the first to incorporate preference uncertainty in a model with dynamic reversion of the status quo.
} 
(Besley and Coate, 1998) often implies muted responses to changing economic conditions and, consequently, provides a rationale for (inefficient) policy conservatism.

Second, in states of disagreement, committee decisions are inertial. That is, the chairman's optimal proposal is often the status quo, even when the state of nature has changed. This result is primarily due to the heterogeneity in policy preferences and to the role of the status quo as the default option in the voting game. Since the default policy may not be undesirable for a committee member, in many instances policy changes are not passed (or proposed). A similar status-quo bias in policy making is derived by Romer and Rosenthal (1978) in a static model. However, compared to their agenda-setting game, the status-quo bias in this model gives rise to inefficiency. In particular, there is imperfect risk-sharing in that there are instances where the current policy is (close to) optimal for one policy maker but very costly for the other (or vice versa). Also, the status-quo bias in this model is not as severe as in the game in Romer and Rosenthal. In some circumstances, the chairman is able to change policy even if the default option coincides with the preferred policy of the other member. This result arises because, in a dynamic setup, committee members smooth their bargaining power across states and are willing to lower their current utility to increase their bargaining power in future meetings.

Simulations of our model confirm that the policy variable changes less often than the state of nature and, consequently, the path of the former is smoother than that of the latter. A similar result whereby committee decision making induces policy smoothing has been derived by Waller (2000) in a model with partisan central bank appointments and exogenous electoral outcomes à la Alesina (1987). In our model, policy smoothing is not sustained by the strategic appointment of moderate committee members (as in Waller's model) or by trigger punishments (as in Alesina's model), but is instead the result of the voting game played by the committee. Moreover, in the above literature, policy smoothing is regarded as welfare increasing because it reduces the uncertainty associated with elections. Thus, a constant policy rule, irrespective of the identity of the winning party, is beneficial to both parties. In our model, preferred policies are not constant but instead vary over time as the state of nature changes. As a result, a constant policy is not optimal and policy inertia moves the economy away from the efficient frontier.

In what follows, Section 2 describes the committee and solves a two-state model that illustrates basic implications of the voting game, Section 3 solves and simulates a more general multi-state model, Section 4 compares the voting model with an endogenous and a fixed default and Section 5 concludes. 


\section{Two-State Model}

This section describes the committee and examines a version of the dynamic voting game with two states of nature. The two-state model is solved for three horizons, namely $\tau=1,2$ and $\infty$. The finite horizon cases $(\tau=1,2)$ are solved analytically by backward induction and the infinite horizon case $(\tau=\infty)$ is solved numerically. Studying the two-state model first helps develop the reader's intuition by illustrating some of our results in the simplest possible setup.

The committee is composed of two agents with heterogenous preferences: $C$ and $P$, where $C$ is the fixed chairman. ${ }^{2}$ In every period, the committee is concerned with selecting the policy variable $x_{t}$ that takes values in the interval $[0,1]$. To make this more concrete, think of the policy variable as the target value of a key nominal interest rate. In each period $t$, the payoff of policy maker $j$, for $j=C, P$, is

$$
U_{j}\left(x_{t}, \varepsilon_{t}\right)=-\left(x_{t}-r_{j}\left(\varepsilon_{t}\right)\right)^{2}
$$

where $r_{j}\left(\varepsilon_{t}\right)$ is $j$ 's state-dependent preferred policy and $\varepsilon_{t}$ is an exogenous shock. For analytical convenience, it is assumed that the probability distribution of $\varepsilon_{t}$ is discrete. In this section, it is also assumed that $\varepsilon_{t}$ can take only two values, $\varepsilon^{1}$ and $\varepsilon^{2}$. The shock follows a Markov chain and its transition matrix has elements $p_{k i}=\operatorname{prob}\left(\varepsilon^{k} \mid \varepsilon^{i}\right) \in(0,1)$ with $i, k=1,2$ and $\sum_{k=1}^{2} p_{k i}=1$. Two states of nature are defined by the possible realizations of $\varepsilon_{t}$. When $\varepsilon_{t}=\varepsilon^{1}$, agents $C$ and $P$ disagree in their preferred instrument values with $r_{C}\left(\varepsilon^{1}\right)=1$ and $r_{P}\left(\varepsilon^{1}\right)=0 .{ }^{3}$ When $\varepsilon_{t}=\varepsilon^{2}, C$ and $P$ 's preferences are perfectly aligned meaning that $r_{C}\left(\varepsilon^{2}\right)=r_{P}\left(\varepsilon^{2}\right)=1 / 2{ }^{4}$ The assumption that bliss points are evenly spaced entails no loss of generality. Each committee member ranks policy sequences according to the expected

\footnotetext{
${ }^{2}$ The assumption of a fixed agenda setter is made for the sake of realism. For example, in the case of the United States, the chairman of the Federal Open Market Committee is (by tradition) the chairman of the Board of Governors, who in turn is appointed by the President for a renewable four-year term. For models of legislative bargaining where the the agenda setter is randomly selected, see Baron (1996) and Baron and Ferjohn (1989).

${ }^{3}$ The converse assumption that $r_{C}\left(\varepsilon^{1}\right)=0$ and $r_{P}\left(\varepsilon^{1}\right)=1$ leads to decision rules that are mirror images of the ones derived here. Hence, the main theoretical implications of the model are robust to using either version of this assumption.

${ }^{4}$ For instance in Clarida et al. (1999, p. 1672), the optimal interest rate response to cost-push shocks depends on a preference parameter while the response to demand shocks depends only on the slope of the IS curve. Thus, two central bankers with different inflation weights in their loss function but identical estimates of the slope parameter will agree in their desired interest rate following a cost-push shock but will disagree following a demand shock.
} 
utility they deliver. The intertemporal utility of member $j$ is

$$
E\left(u_{j}\left(x_{1}, \ldots, x_{\tau}\right)\right)=E\left(\sum_{t=1}^{\tau} \delta^{t-1} U_{j}\left(x_{t}, \varepsilon_{t}\right)\right),
$$

where $\delta \in(0,1)$ is the discount factor, which is the same for both players.

Note that preferences depend on the policy instrument rather than on policy outcomes (say, inflation and unemployment). This approach has two advantages. First, it makes the voting game more tractable because otherwise the private sector's expectations would be a state variable that has to be validated in a rational expectations equilibrium. ${ }^{5}$ Second, it means that the particular economic model that the policy maker believes to be true need not be specified. This is important because anecdotal evidence suggests that policy makers may have different views about how the economy works depending on their background and intellectual environment (see Hetzel, 1998, and Romer and Romer, 2004).

Systematic disagreement over policy may arise from the combination of several factors. First, members may disagree on the "correct" economic model or, if they share a common model, disagree on the empirical estimates of its parameters. For example, members may have different opinions regarding the true natural unemployment rate or the sacrifice ratio. Second, members may differ in their information sets or in the weights they associate to each piece of information. Finally, members may differ in their preferences over economic outcomes. For example, they may attach a larger relative weight to inflation vis à vis unemployment stabilization or give proportionally more importance to the effects of monetary policy decisions on a geographical region or economic sector. ${ }^{6}$

Before discussing how the committee makes decisions, we derive the benchmark first best that an utilitarian social planner would choose. Let $x_{t}^{*}\left(\varepsilon^{i}\right)$ denote the optimal policy when $\varepsilon_{t}=\varepsilon^{i}$ occurs. The first best is a solution to the following problem

$$
\max _{\left\{x_{t}\right\}_{t=1}^{\tau}} \alpha E\left(u_{C}\left(x_{1}, \ldots, x_{\tau}\right)\right)+(1-\alpha) E\left(u_{P}\left(x_{1}, \ldots, x_{\tau}\right)\right),
$$

\footnotetext{
${ }^{5}$ This is a non-trivial fixed point to solve for. The strategy of the private sector depends on the expected voting outcome, but the outcome of the voting game depends on the expectations of the private sector in two ways: 1) directly, because expected inflation affects policy makers' utilities; and 2) indirectly by changing the default payoff, since the real interest rate in case of disagreement is the difference between the nominal status quo policy and expected inflation. For now, we leave this extension to future research.

${ }^{6}$ In the empirical literature, Belden (1989), Havrilesky and Schweitzer (1990), and Gildea (1992) find that district bank presidents tend to prefer tighter monetary policy than members of the Board of Governors in the Federal Open Market Committee (FOMC). Riboni and Ruge-Murcia (2007a) find systematic heterogeneity in the reaction functions of members of the Monetary Policy Committee of the Bank of England. This heterogeneity appears to be related to the nature of the membership and individual career background. Meade and Sheets (2005) report evidence that FOMC district bank presidents react to regional shocks. Chappell et al. (2005, ch. 6.3) document the division within the FOMC between Keynesian and Monetarist members during Arthur Burns' chairmanship.
} 
where $\alpha$ and $(1-\alpha)$, with $0 \leqslant \alpha \leqslant 1$, are, respectively, the weights assigned to $C$ and $P$ in the planner's social welfare function. Obviously, in the state of agreement $x_{t}^{*}\left(\varepsilon^{1}\right)=1 / 2$. In the state of disagreement, the first-order condition of the planner's problem reads

$$
\frac{x_{t}^{*}\left(\varepsilon^{2}\right)-1}{x_{t}^{*}\left(\varepsilon^{2}\right)}=\frac{\alpha-1}{\alpha} .
$$

Thus, $x_{t}^{*}\left(\varepsilon^{2}\right)=\alpha$. When the utilities of $C$ and $P$ are equally weighted, the first best in the state of disagreement coincides with $1 / 2$. If we let $\alpha$ vary between 0 and 1 , any instrument value in the interval $[0,1]$ is first-best since no member can be made strictly better off without making the other member strictly worse off. ${ }^{7}$

Let $q_{t} \in[0,1]$ denote the status quo at time $t$. The committee decides policies sequentially with the following timing. First, the current realization of the shock is observed. Then, the chairman makes a take-it-or-leave-it proposal $x_{t} \in[0,1]$. If the proposal is rejected by $P$, then the status quo persists until the next period. If the proposal is accepted, then $x_{t}$ is implemented and becomes the new status quo for the voting game at time $t+1$. Note that the committee votes on the current policy only and there are no multi-period proposals. ${ }^{8}$ The assumption that the chairman makes take-it-or-leave-it proposals to the committee is not meant to be a literal description of how monetary committees actually work. Instead, it is a modeling device that captures the idea that chairmen usually have more power and influence than their peers.

Institutional evidence indicates that chairmen have some control over the agenda. For example, in many monetary policy committees, the chairman is traditionally the one who formulates the proposal to be voted on. This is the case, for example, in the committees of the Bank of England, the Norges Bank, Reserve Bank of Australia, the Swedish Riksbank, and the U.S. Federal Reserve (see Meier, 2007). ${ }^{9}$ Anecdotal evidence, mostly from former members of the FOMC, shows the preponderant role of the chairman in the decision making process. For instance, Alan Blinder (2004, p. 47) writes that "each member other than Alan Greenspan has had only one real choice when the roll was called: whether to go on record as supporting or opposing the chairman's recommendation, which will prevail in any

\footnotetext{
${ }^{7}$ The first best could also be implemented in a politico-economic equilibrium if one were to assume that the chairman is able to propose a credible state-contingent plan for all future periods in the initial period. Such proposals are ruled out here on the grounds of realism.

${ }^{8}$ In some cases, monetary policy committees do discuss future policy decisions; think, for example, of the bias statement following FOMC meetings which signals the future policy stance. However, it is apparent that the FOMC is not necessarily bound to pursue that policy in the future. For example, statements usually include a escape clause like: "Nonetheless, the Committee will respond to changes in economic prospects as needed to fulfill its obligation to maintain price stability" (see the press release on 10 November 2004).

${ }^{9}$ Chappell et al. (2005, p. 128) point out that "at almost every meeting in our sample, Greenspan spoke first, offered a proposal, and defended it."
} 
case," Laurence Meyer (2004, p. 50) mentions "the chairman's disproportionate influence on FOMC decisions," and Sherman Maisel (1973, p. 124) remarks that "the influence of the Chairman is indeed great." Moreover, as a consequence of the agenda-setting power by the chairman, the final voting outcome may sometimes be different from the policy favored by a majority of members. ${ }^{10}$ On the other hand, anecdotal evidence also indicates that the chairman is not the single decision maker in monetary policy committees. Maisel ( $p$. 124) and Meyer (p. 52) note, respectively, that the Chairman "does not make policy alone" and "does not necessarily always get his way." Similar views are also expressed by Blinder (2007) who argues that the chairman's proposal also reflects the opinions expressed by other committee members.

The problem of the chairman can be formulated recursively with the current status quo and the current shock as states variables. In each period $t$, the proposal strategy $G_{C, t}\left(q_{t}, \varepsilon^{i}\right)$ solves the dynamic programming problem

$$
V_{C, t}\left(q_{t}, \varepsilon^{i}\right)=\max _{x_{t} \in A_{t}\left(q_{t}, \varepsilon^{i}\right)} U_{C}\left(x_{t}, \varepsilon^{i}\right)+\delta \sum_{k=1}^{2} p_{k i} V_{C, t+1}\left(x_{t}, \varepsilon^{k}\right)
$$

for $i=1,2$. In words, $C$ proposes the policy $x_{t}$ that maximizes his lifetime utility from among those that are acceptable to $P .{ }^{11}$ We assume that $P$ accepts a proposal whenever the current utility from the proposal plus the continuation value of moving to the next period with a new status quo is higher than or equal to keeping the status quo and moving to the next period with the current status quo. The set of acceptable policies is denoted by $A_{t}\left(q_{t}, \varepsilon^{i}\right)$ and may be more formally defined as

$A_{t}\left(q_{t}, \varepsilon^{i}\right)=\left\{x_{t} \in[0,1]: U_{P}\left(x_{t}, \varepsilon^{i}\right)+\delta \sum_{k=1}^{2} p_{k i} V_{P, t+1}\left(x_{t}, \varepsilon^{k}\right) \geq U_{P}\left(q_{t}, \varepsilon^{i}\right)+\delta \sum_{k=1}^{2} p_{k i} V_{P, t+1}\left(q_{t}, \varepsilon^{k}\right)\right\}$

for $i=1,2$. Note that the chairman's proposals will never be rejected in equilibrium. ${ }^{12}$ This implication is in line with historical records from the FOMC which show that a chairman's

\footnotetext{
${ }^{10}$ Blinder (2004, p. 47) cites two instances where this appears to have been true for the FOMC. First, transcripts for the meeting on 4 February 1994 indicate that most members wanted to raise the Federal Funds rate by 50 basis points, while Greenspan wanted a 25 point increase. Nonetheless, the committee eventually passed Greenspan's preferred policy. Second, Blinder reports the general opinion that in the late 1990s Greenspan was able to maintain the status quo although most committee members were in favor of an interest rate increase.

${ }^{11}$ On the basis of FOMC transcripts for the period 1987 to 1996, Chappell et al. (2005, p. 186) conclude that "there are at least suggestions that Greenspan's proposals were crafted with knowledge of what other members might find acceptable."

${ }^{12}$ Proposing a policy outside the acceptance set is equivalent to proposing the status quo, which is always accepted.
} 
recommendation has never been voted down by the committee (see, Chappell et al., 2005). ${ }^{13}$ As a solution concept, we adopt Markov perfection. Informally, in a Markov-perfect equilibrium $i$ ) the proposal rules $\left\{G_{C, t}\right\}_{t=1}^{\tau}$ satisfy equation (3) given the acceptance sets $\left\{A_{t}\right\}_{t=1}^{\tau}$ and $i i)\left\{A_{t}\right\}_{t=1}^{\tau}$ are optimal given that $\left\{G_{C, t}\right\}_{t=1}^{\tau}$ describe what would happen if the current proposal were rejected.

Finally, note that unanimity is required for a policy change only because we are considering a two-person committee. Appendix B shows that the voting outcome in our model would be identical to the one that we would obtain in a committee with $n+1$ members where $P$ occupies the role of the median and a simple majority is required to pass a proposal. This result is due to the fact that in a larger committee, the equilibrium outcome would only depend on the preferences of two key players, namely the median and the chairman. Consequently, the voting outcome would not be affected by either $i$ ) an increase of the size of the committee that leaves unchanged the identity of the median or ii) a radicalization of the preferences of all members other than the median and the chairman.

\subsection{Finite Horizon with $\tau=1$}

Consider the voting game described above with finite horizon $\tau=1$. Absent any dynamics, the solution is similar to that of the agenda-setting game studied by Romer and Rosenthal (1978). The chairman's proposal strategy is depicted in the first column of Figure 1 as a function of the status quo $q_{\tau}$ for each possible realization of $\varepsilon_{\tau}$. Proposals on the 45 degree line are the status quo.

First, suppose that $\varepsilon^{1}$ occurs. In this case, the chairman proposes the status quo for any $q_{\tau} \in[0,1]$. The reason is that $P$ would not accept any proposal $x_{\tau} \in\left(q_{\tau}, 1\right]$ that gives $C$ higher utility than $q_{\tau}$, and $C$ would not propose any $x_{\tau} \in\left[0, q_{\tau}\right)$ that gives him lower utility than $q_{\tau}$. Since the proposal strategy is independent of the values of $\delta, p_{11}$ and $p_{22}$, it follows that policy inertia arises in this case only as a result of the heterogeneity among committee members. Now, suppose that $\varepsilon^{2}$ occurs and both members agree that $1 / 2$ is the optimal value of the policy instrument. In this case, the chairman proposes $1 / 2$ starting from any status quo. Notice that the outcome of this static game coincides with the first best.

\footnotetext{
${ }^{13}$ This observation is also generally true for the Monetary Policy Committee of the Bank England. The only exception (out of 108 meetings) is the policy decision on 4 August 2005 when the Governor was outvoted 4 to 5 in favor of an interest rate cut of 25 basis points.
} 


\section{$2.2 \quad$ Finite Horizon with $\tau=2$}

Suppose now that the horizon is $\tau=2$. The equilibrium of this two-period version of the model is solved backwards for $t=\tau, \tau-1$. The proposal strategies in the final period $\tau$ are those derived in Section 2.1. The proposal strategies at time $\tau-1$ are derived in Proposition 1 below. In order to develop the reader's intuition, these strategies are depicted in the second column of Figure 1 in the special case where $\delta=0.5, p_{11}=0.8$ and $p_{22}=0.5$. These probabilities correspond approximately to those computed using the voting records of the Monetary Policy Committee (MPC) of the Bank of England from June 1997 to January $2005 . .^{14}$

Proposition 1. Let $\tau=2$. For all $q_{\tau-1} \in[0,1]$ the proposal rules at time $\tau-1$ when $\varepsilon^{1}$ and $\varepsilon^{2}$ occur are, respectively, $G_{C, \tau-1}\left(q_{\tau-1}, \varepsilon^{1}\right)=q$ and

$$
G_{C, \tau-1}\left(q_{\tau-1}, \varepsilon^{2}\right)=\left\{\begin{array}{ll}
y, & \text { for } q_{\tau-1} \in[0,2 z-y], \text { where } y=\left(1 / 2+\delta p_{12}\right) /\left(1+\delta p_{12}\right), \\
2 z-q, & \text { for } q_{\tau-1} \in(2 z-y, z), \text { where } z=(1 / 2) /\left(1+\delta p_{12}\right), \\
q, & \text { for } q_{\tau-1} \in[z, y], \\
y, & \text { for } q_{\tau-1} \in(y, 1] .
\end{array} .\right.
$$

Proof: See Appendix A.

Note that the decision rules in period $\tau-1$ converge to those in period $\tau$ as $\delta \rightarrow 0$ (committee members attach no weight to future payoffs) or $p_{12} \rightarrow 0$ (the probability of disagreement tends to zero): in either case $y, z \rightarrow 1 / 2$.

We now comment on the policy rules just derived. When $\varepsilon^{1}$ occurs and committee members disagree on the optimal instrument value, the proposal at time $\tau-1$ is the status quo. Thus, in the state of disagreement the entire policy space $[0,1]$ is a gridlock interval. If the status quo falls within this interval, policy changes are blocked by either member of the committee. The status-quo bias originates from the opposite preferences of the two players. In this case, there is no Pareto-improving policy change and the political equilibrium is efficient according to the standard economic definition. To see this, pick any $q_{\tau-1} \in[0,1]$ and note that any policy choice to the right (left) of $q_{\tau-1}$ would reduce $P$ 's $(C$ 's)

\footnotetext{
${ }^{14}$ The voting records contain information on: the date of the meeting; the policy decision; the names of members in favor of the decision; and the names and preferred policy options of dissenting members. The probabilities are computed as follows. A meeting where the policy decision is adopted unanimously is treated as one where all committee members agree in their preferred instrument value, meaning that in terms of our model $\varepsilon_{t}=\varepsilon^{2}$. A meeting with at least one dissenting individual is treated as one where committee members disagree in their preferred instrument value, meaning that $\varepsilon_{t}=\varepsilon^{1}$. Then, $p_{11}\left(p_{22}\right)$ is computed as the number of observations where members disagree (agree) in two consecutive meetings divided by the number of observations where members disagree (agree) in the first of these two meetings. Since the mapping from the voting records to the model is clearly imperfect, the policy rules in Figure 2 are best interpreted as illustrative only.
} 
utility. Thus, for the two-state model, the committee implements the first-best in the state of disagreement. ${ }^{15}$

When $\varepsilon^{2}$ occurs, committee members agree that $1 / 2$ is the optimal instrument value today. If monetary policy were decided by $C$ alone, the instrument value would be adjusted to $1 / 2$. Instead, Proposition 1 shows that the proposal at time $\tau-1$ is generically different from the first-best policy $1 / 2$. For example, when $q_{\tau-1} \in[y, 1]$ the chairman adjusts the current policy only to $y$, which is larger than $1 / 2$. This result is due to the non-zero probability of disagreement in the next meeting. The chairman trades off the benefit of moving towards the ideal point $1 / 2$ and the cost of having a worse status quo should $\varepsilon^{1}$ occur in the next period. In particular, the chairman realizes that any policy change that is implemented in the current period will stay in place in the next period should $\varepsilon^{1}$ occur. The interval of status quo policies where policy change is not possible (i.e., the gridlock interval) is $[z, y]$. Note that policies $z$ and $y$ correspond to the peaks of the two-period expected utility of member $P$ and $C$, respectively. If $q_{\tau-1} \in[z, y], P$ would veto any increase of the instrument value towards $y$ and proposing the status quo is then the best option for the chairman. A policy change can only occur when the status quo is sufficiently extreme. In particular, when $q_{\tau-1}$ falls in the interval $[0, z)$, the chairman proposes $2 z-q_{\tau-1}$, which is the reflection point of $q_{\tau-1}$ with respect to $z$. This proposal is the closest policy to $y$ among the ones that are acceptable by $P$. When instead $q_{\tau-1} \in(y, 1]$, the chairman is able to offer and pass a proposal that coincides with his ideal point $y$. Note that the width of the gridlock interval $[z, y]$ is increasing in the conditional probability of future disagreement $p_{12}$ and decreasing in the discount rate.

To see why committee decision-making is dynamically inefficient, consider, for instance, the case where $q_{\tau-1}=y$. Rather than staying in $y$, as established in Proposition 1, a Paretoimproving choice would be moving to $1 / 2$ today and going back to $y$ in the next period should $\varepsilon^{1}$ occur. However, this policy requires commitment. Absent commitment, after the default policy has changed to $1 / 2$, it is not optimal for $P$ to allow $C$ to return to $y$. Consequently, a policy change to $1 / 2$ will not be implemented by the committee. Similar polices that Pareto-improve upon those in Proposition 1 can be constructed for all status quo in $[0,1]$ except for $\{1 / 2,2 z-1 / 2\}$. (In these two cases, committee decision making implements the first-best because the proposal coincides with 1/2.) Hence, this simple two-state, two-period model illustrates the fact that committee decision making with an endogenous status quo may be inefficient.

\footnotetext{
${ }^{15}$ Section 3 below shows that this result is not robust to increasing the number of shock realizations and, consequently, in the multi-state version of the model, the politico-economic equilibrium is inefficient in all states.
} 
The model has positive implications concerning the size of the policy change approved by the committee compared with the one a single central banker would choose. In what follows, policy conservatism (overshooting) refers to a situation where the committee changes policy by less (more) than $C$ as a single banker would. In the state of disagreement, the committee does not change the instrument value for any initial status quo while the single banker would change it to 1 regardless of the status quo. In the state of agreement, when the status quo falls in the interval $(2 z-1 / 2,1]$, with $2 z-1 / 2$ the reflection point of $1 / 2$ with respect to $z$, the policy change approved by the committee is $\left|q_{\tau-1}-x_{t}\right|$. This change is smaller than $\left|q_{\tau-1}-1 / 2\right|$ which is the adjustment that a single central banker would implement. In the special case where $q_{\tau-1}=2 z-1 / 2$, both the committee and single banker change the instrument value by the same amount. However, if the initial status quo belongs to the interval $[0,2 z-1 / 2)$, the committee overshoots $1 / 2$ and changes the instrument value by more that a single banker would. The reason is that for a sufficiently low status quo, $C$ has enough leverage to propose policies that are larger than $1 / 2$ and closer to his ideal point $y$. Thus, overshooting is just another manifestation of dynamic inefficiency. By inspecting the second column of Figure 1, it is clear that the interval of status quo policies where overshooting arises, $[0,2 z-1 / 2)$, is much smaller than the interval where policy conservatism arises, $(2 z-1 / 2,1]$. Since overshooting may be a possible outcome of committee decision making, its quantitative importance is examined below by means of simulations (see Section 3.2).

It is instructive to consider the implications for monetary policy if instead, as in much of the political economy literature, we were using a median voter approach. In that case, the policy outcome in each meeting would coincide with the interest rate preferred by the median and would be independent from the location of the status quo and from the identity of the chairman. Since the equilibrium outcome in the next period is uniquely pinned down and is not affected by current decisions, there would be no dynamic link across periods and, consequently, the committee would not adjust interest rates in a cautious manner whenever the policy preferences of all members are aligned.

\subsection{Infinite Horizon}

Consider now the voting game in the case where the horizon is infinite. ${ }^{16}$ Because finding the analytical solution to the infinite-horizon game is not trivial, we employ instead a numerical algorithm to find the stationary decision rules. The procedure builds on the projection

\footnotetext{
${ }^{16}$ This is equivalent to assume that, at the end of a finite term in office, a committee member is replaced by another policy maker with the same preferences and that members care about policy outcomes that occur after their mandates.
} 
method employed by Judd (1998) to study the Bellman equation of the stochastic growth model, and works by backward induction exploiting the observation that the chairman's problem is a constrained maximization which can be solved numerically using standard hillclimbing methods. See Appendix C for a detailed description of the algorithm.

The chairman's stationary decision rules are plotted in the third column of Figure 1. When $\varepsilon_{t}=\varepsilon^{1}$ and both members disagree, the chairman simply proposes the status quo. As in the finite horizon model, the gridlock interval is equal to the entire policy space $[0,1]$. When $\varepsilon_{t}=\varepsilon^{2}$, the proposal strategy is qualitatively similar to that derived analytically in Proposition 1 for the horizon $\tau=2$. However, the set of status quo for which the chairman does not propose a policy change is larger and is now equal to the interval $[v, w]$, with $w<z<y<v$. For example, when the status quo is sufficiently high the committee moves to $v$ when $\varepsilon^{2}$ occurs. The difference between the proposed policy and the current bliss point is then larger. Intuitively, as we increase the periods left before the end of the game, the chairman is more cautious in moving towards $1 / 2$ because he is more likely to be constrained as a result of the current choice. Note that today's decision has an effect on future outcomes only when $\varepsilon^{1}$ occurs in the next period, two periods in a row, three periods in a row, etc. When there are more periods left before the end of the game, the sum of the probabilities associated with these events is quantitatively larger.

\section{Multi-State Model}

This section solves the dynamic voting game in the more general case where the number of possible shock realizations is larger than two. This extension is important for two reasons. First, it shows that the efficient outcome in the state of disagreement reported in Section 2 is not robust to increasing the number of shock realizations and, consequently, committee policy choices may be inefficient in all states. Second, the two-state model features a strong form of policy inertia in the form of the absorbing region $[w, v]$ and, consequently, it does not permit the derivation of time series implications. ${ }^{17}$ In what follows, the chairman's proposal strategies are computed, and then policy decisions by the committee are simulated for a sample of sequential meetings.

\subsection{Proposal Strategies}

Assume that the shock $\varepsilon_{t}$ can take $I$ discrete values, $\varepsilon^{i}$ for $i=1,2, \ldots, I$. Define $S=$ $\left\{\varepsilon^{1}, \varepsilon^{2}, \ldots, \varepsilon^{I}\right\}$. As before, the shock follows a Markov chain and its $I \times I$ transition matrix

\footnotetext{
${ }^{17}$ To see this, note that as soon as $\varepsilon_{2}$ occurs, the successful proposal will be $x_{t} \in[w, v]$ with $x_{t}=q_{t} \in[w, v]$ thereafter.
} 
has elements $p_{k i}=\operatorname{prob}\left(\varepsilon^{k} \mid \varepsilon^{i}\right) \in(0,1)$ that satisfy $\sum_{k=1}^{I} p_{k i}=1$. The shock $\varepsilon_{t}$ shifts the agents' preferred policies over a policy set $X=[0,1]$. The timing and other features of the model are as described in Section 2. For any $q_{t} \in X$ and $\varepsilon_{t} \in\left\{\varepsilon^{1} \ldots, \varepsilon^{I}\right\}$, the chairman's proposal strategy $G_{C, t}\left(q_{t}, \varepsilon_{t}\right)$ solves the dynamic programming problem

$$
V_{C, t}\left(q_{t}, \varepsilon_{t}\right)=\max _{x_{t} \in A_{t}\left(q_{t}, \varepsilon_{t}\right)} U_{C}\left(x_{t}, \varepsilon_{t}\right)+\delta E_{t} V_{C, t+1}\left(x_{t}, \varepsilon_{t+1}\right)
$$

For concreteness, we focus on the case where $I=6$ and maintain the convention that committee members agree in the even states and disagree in the odd states of nature. The bliss points of $P(C)$ in states 1 through 6 are, respectively, $0(1 / 2), 1 / 4(1 / 4), 1 / 4(3 / 4)$, $1 / 2(1 / 2), 1 / 2(1)$, and $3 / 4(3 / 4)$.

We now characterize the first-best policy for the multi-state version of the model. As before, $x_{t}^{*}\left(\varepsilon^{i}\right)$ denotes the first-best policy when shock $i$ occurs. Clearly, $x_{t}^{*}\left(\varepsilon^{2}\right)=1 / 4$, $x_{t}^{*}\left(\varepsilon^{4}\right)=1 / 2$, and $x_{t}^{*}\left(\varepsilon^{6}\right)=3 / 4$. Regarding the optimal policies in the states of disagreement, the following risk-sharing conditions must hold:

$$
\frac{x_{t}^{*}\left(\varepsilon^{1}\right)-1 / 2}{x_{t}^{*}\left(\varepsilon^{1}\right)}=\frac{x_{t}^{*}\left(\varepsilon^{3}\right)-3 / 4}{x_{t}^{*}\left(\varepsilon^{3}\right)-1 / 4}=\frac{x_{t}^{*}\left(\varepsilon^{5}\right)-1}{x_{t}^{*}\left(\varepsilon^{5}\right)-1 / 2}=\frac{\alpha-1}{\alpha} .
$$

That is, the ratio of marginal utilities must be equalized across all states of disagreement. The above condition implies that $x_{t}^{*}\left(\varepsilon^{1}\right)=\alpha / 2, x_{t}^{*}\left(\varepsilon^{3}\right)=\alpha 3 / 4+(1-\alpha) / 4$ and $x_{t}^{*}\left(\varepsilon^{5}\right)=$ $\alpha+(1-\alpha) / 2$. As before, the first-best depends on the state of the economy only and not on the time index $t$. Since the ideal points are equally spaced, condition (5) implies that in all states of disagreement, the distance between the ideal point and the first best is constant. That is, $x_{t}^{*}\left(\varepsilon^{1}\right)=x_{t}^{*}\left(\varepsilon^{3}\right)-1 / 4=x_{t}^{*}\left(\varepsilon^{5}\right)-1 / 2$. To see, for example, that $x_{t}^{*}\left(\varepsilon^{1}\right)=x_{t}^{*}\left(\varepsilon^{3}\right)-1 / 4$, suppose, on the contrary, that $x_{t}^{*}\left(\varepsilon^{1}\right)<x_{t}^{*}\left(\varepsilon^{3}\right)-1 / 4$ and note that in this case both policy makers could augment their payoff by increasing $x_{t}^{*}\left(\varepsilon^{1}\right)$ and lowering $x_{t}^{*}\left(\varepsilon^{3}\right)$. However, this Pareto improving policy change requires commitment. Absent commitment, $C$ will not, in general, abide by his promises after $P$ concedes to change the interest rate. Results below show that the committee does not implement the first-best policy. First of all, the policy in the state of agreement will be different from the unanimously preferred policy. Moreover, in the states of disagreement condition (5) will not be satisfied: there are instances where the current policy is (close to) optimal for one policy maker but very costly for the other (or vice versa).

The stationary decision rules of the dynamic voting game are solved for using the algorithm described in Appendix C. Since the chairman's proposal strategies depend on the matrix of transition probabilities, we conducted extensive experiments with various parame- 
ter configurations and report below results for $\delta=0.5$ and the transition matrices ${ }^{18}$

$$
A=\left[\begin{array}{cccccc}
3 / 5 & 1 / 5 & 0 & 0 & 0 & 0 \\
1 / 5 & 3 / 5 & 1 / 5 & 0 & 0 & 0 \\
1 / 5 & 1 / 5 & 3 / 5 & 1 / 5 & 0 & 0 \\
0 & 0 & 1 / 5 & 3 / 5 & 1 / 5 & 1 / 5 \\
0 & 0 & 0 & 1 / 5 & 3 / 5 & 1 / 5 \\
0 & 0 & 0 & 0 & 1 / 5 & 3 / 5
\end{array}\right] \text { and } B=\left[\begin{array}{cccccc}
1 / 6 & 1 / 6 & 1 / 6 & 1 / 6 & 1 / 6 & 1 / 6 \\
1 / 6 & 1 / 6 & 1 / 6 & 1 / 6 & 1 / 6 & 1 / 6 \\
1 / 6 & 1 / 6 & 1 / 6 & 1 / 6 & 1 / 6 & 1 / 6 \\
1 / 6 & 1 / 6 & 1 / 6 & 1 / 6 & 1 / 6 & 1 / 6 \\
1 / 6 & 1 / 6 & 1 / 6 & 1 / 6 & 1 / 6 & 1 / 6 \\
1 / 6 & 1 / 6 & 1 / 6 & 1 / 6 & 1 / 6 & 1 / 6
\end{array}\right]
$$

Matrix $A$ was deliberately designed to represent the idea that preferred policies evolve slowly over time as new information about business cycle and inflation variables becomes available. Matrix $B$ is used to study committee decision making when the states of nature are serially uncorrelated. Decision rules are respectively plotted in the first and second column of Figure 2. Proposals on the 45 degree line are the status quo (that is, $x_{t}=q_{t}$ ).

The following implications for committee decision making can be drawn from Figure 2. First, consider the proposal rules in states of agreement. As before, the chairman proposes instrument values different from $1 / 4,1 / 2$ and $3 / 4$ in states 2,4 and 6 , respectively, even though both members agree that these are their current preferred policy options. The intuition for this result is the same as in the two-state model, namely that in a dynamic setup, committee members face a trade-off between the current benefit of choosing their preferred policy and the possible cost of reducing their bargaining power in future meetings. In most cases, the committee partially adjust to shocks that align preferences and, consequently, policy changes are typically smaller than the optimal ones.

Now consider the proposal rules in states of disagreement. In these cases, there is local policy inertia around previously agreed on decisions. To see this, consider the following example. Starting from state $\varepsilon_{t}=\varepsilon^{2}$ and instrument value $1 / 4$, suppose there is a "small" change in the state of nature, meaning to either of the adjacent states $\varepsilon_{t}=\varepsilon^{1}$ or $\varepsilon^{3}$. In these states, members disagree on their preferred instrument value but the chairman's decision rule still implies $x_{t}=1 / 4$. Now, suppose there is a "large" change in the state of nature, meaning to $\varepsilon_{t}=\varepsilon^{4}, \varepsilon^{5}$ or $\varepsilon^{6}$. Note that in these cases the proposal will be different from the status quo regardless of whether members agree in their desired instrument value or not. An implication of local inertia is that the relation between changes in the state of nature and in policy is nonlinear. In particular, small changes in the state of nature are less likely to produce policy changes compared with larger ones. Empirically, this would mean, for example, that small variations in the rates of inflation and unemployment are less

\footnotetext{
${ }^{18}$ The relatively low value of $\delta$ is used to show that dynamic inefficiency arises in the multi-state version of the model even when the future is heavily discounted. Alesina (1987) argues that policy makers' effective discount rates may be low because reappointment probabilities are less than one. Results from unreported experiments are available from the corresponding author upon request.
} 
likely to result in a change in the key nominal interest rate, compared with large movements in these variables. ${ }^{19}$ In contrast, the standard model with a single central banker, which underlies the derivation of the linear Taylor rule, predicts a proportional change in the policy instrument for any change in inflation and unemployment regardless of their size.

Note that $P$ allows a policy change in the (odd) states of nature where there is disagreement, even when the current default coincides with his preferred policy. For example, when $q=0$ and $\varepsilon_{t}=\varepsilon^{1}$ occurs, the committee chooses an instrument value closer to $1 / 2$. When the default coincides with his preferred policy, $P$ has significant bargaining power in the current period and, consequently, is willing to accept a policy change to increase his bargaining power in future meetings. (Notice that were policy $x_{t}=0$ to remain the default and should $\varepsilon_{5}$ occur next period, $P$ would enter the next meeting with very low bargaining power.) This result is not present in the static agenda-setting game of Romer and Rosenthal (1978). It can only be obtained in a dynamic setup where agents have an incentive to smooth their bargaining power across states by choosing the default for the next meeting. ${ }^{20}$ This opportunity is valuable because agents are risk-averse. In absence of commitment, agents strategically modify the (endogenous) default in order to better share risk across states. Clearly, this instrument is imperfect: compared to what is prescribed by the first-best, risk-sharing is not optimal (i.e., the politico-economic equilibrium fails to satisfy the efficiency condition in states of disagreement as well). In some states, one of the two policy makers obtains a high payoff while the other suffers a large loss; in some other states, the situation may be reversed. Consequently, there is room for better risk-sharing among committee members.

\subsection{Simulations}

This section simulates committee decision making using an artificial sample of sequential meetings under the multi-state voting model examined above. This exercise is important because it reveals the proposal strategies that are implemented in practice and permits the derivation of time series implications.

A series of 200 realizations of the shock $\varepsilon_{t}$ were generated using each transition probability matrix (whether $A$ or $B$ ). Then, the outcome of the voting game was found using the chairman's proposal strategies in Figure 2. The simulated series of $\varepsilon_{t}$ and $x_{t}$ are plotted in Figure 3. Notice that there is policy smoothing in the sense that the policy variable changes less often than the state of nature. That is, there are many instances where nature changes

\footnotetext{
${ }^{19}$ Eijffinger, Schaling and Verhagen (1999) and Guthrie and Wright (2004) construct models for a single central banker that generate a similar prediction in the form of an inaction range around the previous policy choice, but inertia is the result of unspecified costs for policy changes.

${ }^{20}$ This result is also present in Baron (1996) and Bullard and Waller (2004).
} 
but the value of the policy variable remains the same. Also, notice that the ergodic process of the policy variable involves a finite number of realizations but they do not correspond to the agreement values $(1 / 4,1 / 2$, and $3 / 4)$ because of dynamic inefficiency. Earlier research by Alesina (1987) and Waller (2000) also finds that policy may display less variance when decisions are made through committees than when they are made by a single individual. However, in this model, policy $x_{t}$ is not sustained by the strategic appointment of moderate committee members (as in Waller's model) or by trigger punishments (as in Alesina's model), but by the voting game played by the heterogenous committee.

From the simulated series, it is possible to construct the unconditional distribution of $\Delta x_{t}$ in Figure $4 .^{21}$ From this Figure, it is clear that the most common policy decision by the committee is to set $\Delta x_{t}=0$ despite the fact that the state of nature has changed. ${ }^{22}$ This result is due to the local inertia implied by the optimal decision rules of committee members. This prediction of the voting model is in line with observations of actual policy decisions. For example, Figure 5 plots the unconditional distribution of changes in the target value of the key interest rate in four central banks: the U.S. Federal Reserve, the European Central Bank, the Bank of England, and the Bank of Canada. ${ }^{23}$ Notice that in the data, the unconditional distribution of interest rate changes also has a mode equal to zero.

It is important to compare this implication with the one obtained when monetary policy is determined by a single individual, say $C$. Absent a committee, $C$ 's decision rule involves changing the policy variable to his preferred value whenever there is a change in the state of nature. The histograms for this case are plotted in the bottom panel of Figure 4 and show that, in contrast with the data, the outcome $\Delta x_{t}=0$ is relatively infrequent.

Although overshooting is a possibility in our model, we find that policy conservatism is by far the most common outcome. Under Matrix $A$, the size of $\Delta x_{t}$ is always smaller when decisions are made by the committee rather than by $C$ alone, while under Matrix $B$, it is so 80 per cent of the times. ${ }^{24}$

\footnotetext{
${ }^{21}$ In order to get a more accurate picture of the distribution, these histograms were constructed using simulations of 10000 observations.

${ }^{22}$ Because the transition matrix has a built-in inertia when the diagonal elements are non-zero and in order not to overstate the policy inertia predicted by the voting game, the histograms are plotted using only observations where there is a change in the state of nature.

${ }^{23}$ The interest rates are the Federal Funds Rate, the Rate for Main Refinancing Operations, the Repo Rate, and the Overnight Rate, respectively. The samples used to construct these histograms start in August 1987, January 1999, June 1997, and December 2000, respectively, and end in May 2006 in all cases. For the Federal Reserve, the data sources are Chappell et al. (2005) and the Federal Reserve Bank of New York. For the other central banks, the data were collected by the authors using official press releases.

${ }^{24}$ Looking at the policy rules in Figure 2, an example of overshooting under Matrix $B$ is the following. Starting in state $\varepsilon_{t}=\varepsilon^{2}$ and with a status quo larger than $1 / 4$, note that the chairman proposes a policy less
} 
Figure 6 plots the sample autocorrelation of the policy variable in the model and in the key interest rate from four central banks. First, note that the model endogenously generates positive autocorrelation in the policy variable even when the states of nature are not serially correlated (Matrix B). The reason is simply that, since the status quo is a state variable, current and lagged instrument values are linked through the solution of the chairman's dynamic optimization problem. Second, when the states of nature are persistent (Matrix A), then the predicted autocorrelation may approach that observed in actual data. ${ }^{25}$ In contrast, the standard model with a single central banker, used to derive the Taylor rule, generates interest rate autocorrelation only from the serial correlation of inflation, unemployment, and/or exogenous disturbances. Since interest rates are highly autocorrelated in the data, the empirical analysis of Taylor rules usually involves the addition of lagged interest rates to the theoretical relation. ${ }^{26}$

\section{Comparing Monetary Policy Institutions}

This paper shows the existence of a political failure in monetary policy making by committee. However, the fact that a fictional social planner can improve upon committees is no reason to conclude that this institutional arrangement is inefficient. In the real world, the only fair comparison is among political equilibria that can be obtained in the class of available institutions. ${ }^{27}$ In order to conclude that a given institution is inefficient, one must show that there exists another institution that increases the utilities of both policy makers. Unfortunately, this question cannot be answered in a definitive way because, for obvious reasons, the set of feasible institutions cannot be fully characterized. ${ }^{28}$

In this section, we consider an alternative institutional arrangement that is identical to the one we have discussed so far, except for the fact that the default policy is fixed. This shuts down the dynamic link between periods and eliminates the rationale for not implementing the preferred policy in the even states of nature. Figure 7 shows the stationary policy

than $1 / 4$, while the single central banker would have adopted $1 / 4$. The reason why we observe overshooting with matrix $B$, but not with matrix $A$, is the following. The rationale for overshooting and proposing a policy less than $1 / 4$ is to have more leverage should $\varepsilon_{t}=\varepsilon^{5}$ occur and get closer to the ideal point 1 . The cost of overshooting is that the chairman is worse off if shock $\varepsilon^{1}$ occurs, because the agenda setter is stuck with a policy lower than $1 / 4$, when his ideal instrument value is $1 / 2$. Since $p_{52}=0$ in matrix $A$, the expected cost of overshooting is larger, and, consequently, overshooting does not occur in equilibrium.

${ }^{25}$ English et al. (2003) reports evidence that the autocorrelation in the U.S. Federal Funds Rate is the result of both policy inertia and shock persistence.

${ }^{26}$ See, for example, Clarida et al., (2000). An exception is Woodford (2003) where a motive for interest-rate smoothing is explicitly introduced into the central bank's objective function.

${ }^{27}$ For a discussion along the same lines, see Besley and Coate (1998, Section IV).

${ }^{28} \mathrm{~A}$ recent contribution that analyses alternative institutional arrangements for monetary policy is Bullard and Waller (2004) 
rules under different defaults. These policy rules do not depend on either the status quo or the matrix of transition probabilities. That is, when plotted as a function of $q_{t}$, they are horizontal lines and are the same for any transition matrix. The optimal proposal in the even states of nature is the preferred bliss point for any fixed default, but in the odd states it crucially depends on the location of the default. Table 1 reports the ex-ante (average) payoff for each committee member under three alternative institutions: $i$ ) a committee with an evolving default; ii) a committee with a fixed default; and iii) full delegation to $C .{ }^{29}$

Table 1 shows that a redistribution of utilities across members is obtained by varying the fixed default. Note that the "average" preferred policies in the states of disagreement for $P$ and $C$ are, respectively, $1 / 4$ and $3 / 4$. This is why $P(C)$ obtains a high payoff when $1 / 4(3 / 4)$ is the fixed default. However, the best fixed default for the chairman is policy 1. The reason is that this default always gives $P$ a lower payoff than $C$ 's ideal point. Thus, the chairman has enough bargaining power to propose his preferred point in all states of nature. Having a committee with a fixed default at 1 is therefore equivalent to an institution where $C$ is the single central banker (see the last column in Table 1). Note that while having a fixed default eliminates the dynamic inefficiency in the states of agreement, it does not implement the efficient outcome in the states of disagreement. To see this, suppose, for example, that the fixed default is $1 / 2$. Then, the committee selects $1 / 2$ whenever $\varepsilon_{t}=\varepsilon^{1}$ or $\varepsilon_{t}=\varepsilon^{5}$ occur. This outcome is clearly inefficient because the utility of both committee members would increase by choosing a policy between the values preferred by $P$ and $C$. In other words, there is inefficient risk sharing between $P$ and $C$ when the default is fixed. This source of inefficiency is also present in the model with an endogenous default, but it is less severe. The reason is that, when the default is endogenous, committee members can smooth their bargaining power across states of natures and, consequently, insure themselves against the eventuality of having little bargaining power in the next meeting.

Now, compare the average payoffs under committees with endogenous and fixed defaults. Clearly, an endogenous default lowers the average payoff to both members in the even states compared with a fixed default because the policy preferred by both members is not implemented. However, Table 1 shows that starting with an endogenous default, the committee would not agree on amending the institution because any choice of fixed default would lower the ex-ante utility of one of the policy makers. Table 1 also shows that, when the default is endogenous, $C$ obtains a larger share of the surplus when the transition matrix is $B$ rather

\footnotetext{
${ }^{29}$ This comparison is meant to be suggestive only. The stylized nature of the model developed here prevents us from assessing more in detail the potential social welfare implications of committee decisionmaking, as well as the empirical relevance of dynamic inefficiency. We intend to take up these issues in future work.
} 
than $A$. This is so because the optimal policy changes more drastically when shocks follow Matrix $B$. Since the preferred policy in each period is more likely to be far from the previous policy, the chairman has more leverage in proposing his preferred instrument value.

Regarding the variance of policy decisions under these institutions, note that a committee with an endogenous status quo generally lowers the variance of both $x_{t}$ and $\Delta x_{t}$ compared with a single central banker and a committee with a fixed default (except when the default is $1 / 2$ ). This result is a consequence of the local policy inertia introduced by the endogenous status quo.

The absence of an institution that Pareto-dominates an arrangement with an endogenous default can explain its endurance, but it cannot explain why this institutional feature is observed so often in practice. ${ }^{30}$ To answer this question, Riboni (2004) shows that, in a model without uncertainty, an endogenous default works as a commitment device and makes credibility problems less severe.

\section{Discussion and Summary}

This model is a stylized, rather than a literal, description of actual monetary policy committees. In particular, one dimension in which our model differs from actual committees is that in practice terms of office are often staggered. For instance, the terms of the seven members of the Board of Governors of the FOMC last 14 years and are staggered so that one term expires on each even-numbered year. ${ }^{31}$ To study the consequences of staggered terms, Appendix D considers a version of our model that combines finite terms with staggered membership. Thus, members differ not only in their period utility, but also according to the number of periods remaining until the end of their term. To make the set up more tractable, it is assumed that terms last two periods. At each point in time, the committee consists of a junior member, whose term has just began, and a senior member, who is at the end of his term. ${ }^{32}$ Proposals are always made by the senior member, who plays the role of chairman. Results show complete gridlock in the state of disagreement and somewhat less inertia in the state of agreement compared to the model in Section 2.2. The latter result is

\footnotetext{
${ }^{30}$ On this point, see Tsebelis (2002, p. 8). Rasch (2000) identifies countries where an evolving default is part of the formal rules in legislative decision making.

${ }^{31}$ Committees with finite and staggered terms have been studied by Waller (2000). Waller and Walsh (1996) examine the optimal term length in policy boards.

${ }^{32}$ As in the main model, we assume that the time horizon is certain and abstract from the possibility of reappointment. If reappointment is possible, voting decisions may be also driven by the incentive to obtain an additional mandate. In the FOMC, the presidents of the Federal Reserve Banks may be reappointed, but not the members of the Board of Governors (except for the chairman and vice chairman). In the ECB, the terms of office of the members of the Executive Board are not renewable.
} 
mainly due to the fact that when terms are staggered, some committee members (one in our model) are at the end of their terms and, consequently, they do not care about the long-run consequences of changing current policy. ${ }^{33}$ Overall, as in the original version of the model, committees with staggered terms continue to deliver a gridlock interval in both states of nature and choose policies different from first-best.

It is important to emphasize that the mechanism that gives rise to dynamic inefficiency in this model is not specific to the protocol employed. For instance, in related work, we study a different voting procedure where the agenda is predetermined, rather than controlled by the chairman (see Riboni and Ruge-Murcia, 2007b). More precisely, it is assumed that in each meeting, the committee votes over incremental changes from the status quo. For example, an increase of 25 basis points is initially put to a vote against the status quo. If it passes, an increase of 50 basis points is voted against an increase of 25 basis points, and so forth, until further increases are voted down. In order to capture the notion of consensus, it is also assumed that a super-majority (that is, a majority larger than 50 percent plus one of the votes) is required to pass a proposal. In states of disagreement, this protocol generates a gridlock interval where the interest rate selected by the committee is simply the status quo. As the size of the required super-majority increases, the gridlock interval expands and inertia is more pronounced. Only when the status quo is sufficiently extreme, compared with the values preferred by most members, will the committee agree to change the status quo. However, due to the super-majority requirement, the committee will not select the median's preferred policy and will reject further policy changes before it reaches the median's peak. This consensus-based protocol shows that the assumption that the chairman makes take-it-or-leave-it offers to the committee is not necessary to generate a gridlock interval in states of disagreement. Moreover, in states of agreement, this protocol would also generate dynamic inefficiency to the extent that members do not fully adjust the policy instrument. The underlying reason being that a policy change in the current meeting determines, via the endogenous status quo, which policy in the gridlock interval the committee will end up with in case of future disagreement.

Finally, we want to make clear that this paper does not intend to play down the advantages of policy making by committees. First, there might be other reasons that are not captured in our model that make inertia in monetary policy decisions optimal. ${ }^{34}$ Overall,

\footnotetext{
${ }^{33}$ Recall from the discussion in Section 2.3 that as horizon becomes shorter the width of the gridlock interval decreases. In a different set up, Waller (1992) shows instead that increasing term length decreases the variance of policy decisions that is due to electoral uncertainty.

${ }^{34}$ Other explanations for partial adjustment include policy maker uncertainty (Orphanides, 2003), better control over long-term interest rates (Goodfriend, 1991), and reduction of financial stress (Cukierman, 1991). A status-quo bias could also arise from behavioral considerations. Experimental evidence and field studies
} 
it is then entirely possible that the additional policy inertia introduced by monetary policy committees may provide a net benefit to society. Second, beside its implication in terms of inertial behavior, group decision making has many desirable attributes. Previous literature shows that committees can help overcome credibility problems. Sibert (2003) studies the conditions under which committees have more incentives to build reputation than do individual central bankers. In Dal Bó (2006), committee decision making under a supermajority voting rule is able to deliver an ideal balance between commitment and flexibility. Second, another body of literature sees information sharing as the main rationale for committee decision making. This argument goes back to the celebrated Condorcet jury theorem. For example, Gerlach-Kristen (2006) shows that in presence of uncertainty about potential output, voting by committees leads to more efficient signal extraction. Experimental studies by Blinder and Morgan (2000) and Lombardelli et al. (2005) provide some support for this conclusion.

In summary, this paper models monetary policy making as a dynamic non-cooperative game. Committee members sequentially decide the policy for the period after observing the current realization of a preference shock. Depending on the shock, policy makers may agree or disagree about the optimal monetary stance for the period. In this model, the first-best policy can be easily characterized: it satisfies a risk-sharing condition in the states of disagreement and prescribes the preferred policy of both agents in the states of agreement. This paper shows that, in the absence of commitment, committee decision making does not implement the first-best. Inefficiencies arise in all states of nature. In states of agreement, policy makers do not choose the policy they both currently prefer, because they face a tradeoff between the benefit of selecting their preferred policy in the current period and the cost of reducing their bargaining power in the future. In states of disagreement, inefficiency is due to incomplete risk-sharing between committee members. Stochastic simulations show that committee decision making $i$ ) induces policy smoothing in the sense that the policy variable changes less often than the state of nature and ii) endogenously generates autocorrelation in interest rates. Finally, we analyze committee decision making with a fixed default and show that this alternative arrangement removes the inefficiency in states of agreement by eliminating the incentive to smooth bargaining power across states. However, compared to a model with an endogenous default, a fixed default model delivers more inefficient risk-sharing in the states of disagreement. This may be a probable reason why, despite the inefficiencies described, policy making in practice often features an evolving default.

(e.g., Samuelson and Zeckhauser, 1986) indicate that individuals disproportionately favor the status quo. How these considerations play out in a collective decision-making context is a question that to our knowledge, has not yet been addressed either theoretically or empirically in the literature. 
Table 1. Comparison of Voting Models with Endogenous and Fixed Default

\begin{tabular}{|c|c|c|c|c|c|c|c|}
\hline \multirow[b]{2}{*}{ Variable } & \multirow[b]{2}{*}{ Endogenous } & \multicolumn{5}{|c|}{ Fixed } & \multirow{2}{*}{$\begin{array}{c}\text { Single } \\
\text { Banker }\end{array}$} \\
\hline & & 0 & $1 / 4$ & $1 / 2$ & $3 / 4$ & 1 & \\
\hline \multicolumn{8}{|c|}{ Matrix $A$} \\
\hline$C^{\prime}$ s mean payoff & -0.85 & -0.59 & -1.23 & -0.92 & -0.17 & 0 & 0 \\
\hline$P^{\prime}$ s mean payoff & -0.51 & -0.92 & -0.26 & -0.59 & -1.48 & -1.99 & -1.99 \\
\hline $\operatorname{Var}\left(x_{t}\right)$ & 0.58 & 1.13 & 0.83 & 0.50 & 0.75 & 0.96 & 0.96 \\
\hline $\operatorname{Var}\left(\Delta x_{t}\right)$ & 0.27 & 0.78 & 0.45 & 0.44 & 0.77 & 0.95 & 0.95 \\
\hline \multicolumn{8}{|c|}{ Matrix $B$} \\
\hline$C^{\prime}$ s mean payoff & -0.68 & -0.82 & -1.00 & -0.83 & -0.17 & 0 & 0 \\
\hline$P^{\prime}$ s mean payoff & -1.05 & -0.83 & -0.33 & -0.82 & -1.49 & -1.99 & -1.99 \\
\hline $\operatorname{Var}\left(x_{t}\right)$ & 0.75 & 1.29 & 0.90 & 0.58 & 0.75 & 0.96 & .96 \\
\hline $\operatorname{Var}\left(\Delta x_{t}\right)$ & 0.88 & 1.82 & 1.27 & 0.82 & 1.05 & 1.35 & 1.35 \\
\hline
\end{tabular}

Notes: The numbers in this Table were computed using 10000 simulations. 


\section{A Proof of Proposition 1}

We start by showing that $G_{C, \tau-1}\left(q_{\tau-1}, \varepsilon^{1}\right)=q_{\tau-1}$ is the optimal proposal rule. Suppose that the current shock is $\varepsilon^{1}$. The chairman's proposal strategy at time $\tau-1$ is found by exploiting the fact that the successful proposal at time $\tau$ will be given by the proposal rules in Section 2.1. The chairman chooses the proposal $x_{\tau-1}$ that maximizes his two-period payoff within the acceptance set, $A_{\tau-1}\left(q_{\tau-1}, \varepsilon^{1}\right)$. That is, he solves the problem

$$
\max _{x_{\tau-1} \in A_{\tau-1}\left(q_{\tau-1}, \varepsilon^{1}\right)}-\left(1+\delta p_{11}\right)\left(x_{\tau-1}-1\right)^{2},
$$

where

$$
A_{\tau-1}\left(q_{\tau-1}, \varepsilon^{1}\right)=\left\{x_{\tau-1} \in[0,1]:-\left(1+\delta p_{11}\right)\left(x_{\tau-1}\right)^{2} \geq-\left(1+\delta p_{11}\right)\left(q_{\tau-1}\right)^{2}\right\} .
$$

It is easy to see that the acceptance set is $\left[0, q_{\tau-1}\right]$ for any $q_{\tau-1} \in[0,1]$. Since $C^{\prime}$ 's two-period payoff is increasing in the current proposal, the chairman always proposes $x_{\tau-1}=q_{\tau-1}$.

Now we prove that the posited $G_{C, \tau-1}\left(q_{\tau-1}, \varepsilon^{2}\right)$ is optimal. When $\varepsilon^{2}$ occurs at time $\tau-1$, the chairman's problem becomes:

$$
\max _{x_{\tau-1} \in A_{\tau-1}\left(q_{\tau-1}, \varepsilon^{2}\right)}-\left(x_{\tau-1}-1 / 2\right)^{2}-\delta p_{12}\left(x_{\tau-1}-1\right)^{2},
$$

where

$A_{\tau-1}\left(q_{\tau-1}, \varepsilon^{2}\right)=\left\{x_{\tau-1} \in[0,1]:-\left(x_{\tau-1}-1 / 2\right)^{2}-\delta p_{12}\left(x_{\tau-1}\right)^{2} \geq-\left(q_{\tau-1}-1 / 2\right)^{2}-\delta p_{12}\left(q_{\tau-1}\right)^{2}\right\}$.

In finding $G_{C, \tau-1}\left(q_{\tau-1}, \varepsilon^{2}\right)$, it is useful to first derive $P$ 's voting rules. P's two-period utility is concave in $x$, with a maximum at

$$
z=\frac{1 / 2}{1+\delta p_{12}}
$$

Note that $0<z<1 / 2$. Because the payoff is symmetric around $z$, the acceptance set is easy to derive. For any $q_{\tau-1} \in[0, z], A_{\tau-1}\left(q_{\tau-1}, \varepsilon^{2}\right)=\left[q_{\tau-1}, 2 z-q_{\tau-1}\right]$, and for any $q_{\tau-1} \in[z, 1], A_{\tau-1}\left(q_{\tau-1}, \varepsilon^{2}\right)=\left[2 z-q_{\tau-1}, q_{\tau-1}\right]$. Now consider $C^{\prime}$ 's proposal strategy. $C^{\prime}$ 's objective function is concave and has a global maximum at

$$
y=\frac{1 / 2+\delta p_{12}}{1+\delta p_{12}} .
$$

Note that $1 / 2<y<1$. When $q_{\tau-1} \in[y, 1], C$ is not constrained and will propose $y$. When $q_{\tau-1} \in(2 z-y, y), C$ is constrained and proposes his preferred policy in the acceptance set. We distinguish two cases: when $q_{\tau-1} \in[z, y)$, the proposal is $x_{\tau-1}=q_{\tau-1}$, and when $q_{\tau-1} \in(2 z-y, z)$, the proposal is $x_{\tau-1}=2 z-q_{\tau-1}$. Finally, when $q_{\tau-1} \in[0,2 z-y]$, the acceptance set includes $C$ 's bliss point $y$ and, consequently, $C$ proposes $x_{\tau-1}=y$. 


\section{B Committee with $\mathrm{n}+1$ Members}

Consider a committee composed of $n+1$ members. Let $n$ be odd and $[\underline{x}, \bar{x}]$ denote the policy space where policies take value. For a policy change, the chairman needs $(n+1) / 2$ favorable votes besides his own. Each member other than the chairman is indexed by $j$, with $j \in N=\{1, \ldots, n\}$. When $\varepsilon_{t}=\varepsilon^{1}$, members disagree in their preferred instrument values, $r_{j}\left(\varepsilon^{1}\right)$. We order the $n$ members other than the chairman so that member $1(n)$ is the one with the smallest (largest) preferred value under shock $\varepsilon^{1}$, and $r_{1}\left(\varepsilon^{1}\right) \leq r_{2}\left(\varepsilon^{1}\right) \leq \ldots \leq r_{n}\left(\varepsilon^{1}\right)$. The median $m$ is the one with index $(n+1) / 2$. When $\varepsilon_{t}=\varepsilon^{2}$, all members agree and $1 / 2 \in(\underline{x}, \bar{x})$ is their preferred point. We assume that 1 and 0 are, respectively, the preferred values of the chairman and the median, with $\underline{x} \leq 0<1 / 2<1 \leq \bar{x}$. As before, we assume that at time $t$ member $j$ accepts proposal $x_{t}$ if and only if

$$
U_{j}\left(x_{t}, \varepsilon^{i}\right)+\delta \sum_{k=1}^{2} p_{k i} V_{j, t+1}\left(x_{t}, \varepsilon^{k}\right) \geq U_{j}\left(q_{t}, \varepsilon^{i}\right)+\delta \sum_{k=1}^{2} p_{k i} V_{j, t+1}\left(q_{t}, \varepsilon^{k}\right) .
$$

This requirement, which is stricter than sequential rationality when $n \geq 3$, rules out equilibria where players accept a proposal they do not like for the simple reason that a single rejection does not affect the voting outcome (see Baron and Kalai, 1993). The acceptance set is then defined as

$$
A_{t}\left(q_{t}, \varepsilon^{i}\right)=\left\{x_{t} \in[\underline{x}, \bar{x}]: \mid\left\{j \text { accepts } x_{t}\right\} \mid \geq(n+1) / 2\right\} .
$$

Denote by $r_{t}^{i}$ a policy at time $t$ under the shock $\varepsilon^{i}$. Note that the proposal made by the chairman concerns only the current period. However, in order to accept or reject the proposal, members implicitly compare two sequences of policies, where future policies are derived by using the proposal rules for subsequent periods.

Lemma B1. Suppose $\tau \leq \infty$. Let $\left\{\widetilde{r}_{s}^{1}, \widetilde{r}_{s}^{2}\right\}_{s=t}^{\tau}$ and $\left\{\widehat{r}_{s}^{1}, \widehat{r}_{s}^{2}\right\}_{s=t}^{\tau}$ be two arbitrary policy sequences specifying the instrument value for each state starting from an arbitrary $t$. The difference between the utilities associated with these two sequences is a monotone function of $r_{j}\left(\varepsilon^{1}\right)$.

Proof: Without any loss of generality, suppose that the current shock is $\varepsilon^{1}$. Write the expected utility associated with the sequence $\left\{\widetilde{r}_{s}^{1}, \widetilde{r}_{s}^{2}\right\}_{s=t}^{\tau}$,

$$
E_{t}\left(\sum_{s=t}^{\tau} \delta^{s-t} U_{j}\left(\widetilde{r}_{s}, \varepsilon_{s}\right)\right)=-\left(\widetilde{r}_{s}^{1}-r_{j}\left(\varepsilon^{1}\right)\right)^{2}-\delta p_{11}\left(\widetilde{r}_{s+1}^{1}-r_{j}\left(\varepsilon^{1}\right)\right)^{2}-\delta p_{21}\left(\widetilde{r}_{s+1}^{2}-1 / 2\right)^{2}+\ldots,
$$

and with the alternative sequence $\left\{\widehat{r}_{s}^{1}, \widehat{r}_{s}^{2}\right\}_{s=t}^{\tau}$,

$$
E_{t}\left(\sum_{s=t}^{\tau} \delta^{s-t} U_{j}\left(\widehat{r}_{s}, \varepsilon^{s}\right)\right)=-\left(\widehat{r}_{s}^{1}-r_{j}\left(\varepsilon^{1}\right)\right)^{2}-\delta p_{11}\left(\widehat{r}_{s+1}^{1}-r_{j}\left(\varepsilon^{1}\right)\right)^{2}-\delta p_{21}\left(\widehat{r}_{s+1}^{2}-1 / 2\right)^{2}+\ldots
$$


Compute the derivative of the difference of these two utilities with respect to $r_{j}\left(\varepsilon^{1}\right)$ and note that it does not depend on $r_{j}\left(\varepsilon^{1}\right)$. Thus, the difference in utility among any two sequences is monotone in $r_{j}\left(\varepsilon^{1}\right)$.

From this lemma, we can prove the following proposition:

Proposition B1. A proposal is accepted if and only if it is accepted by the median.

Proof: Let $G_{C, t}\left(q_{t}, \varepsilon_{t}\right)$ denote the proposal rule that all members expect from the chairman. Notice that knowing $G_{C, t}\left(q_{t}, \varepsilon_{t}\right)$, each member is able to foresee all the policies that the committee will implement if the current proposal $x_{t}$ is passed. The utility associated to this sequence is compared to the one obtained if the current status quo is kept for one more period. Suppose that the median accepts proposal $x_{t}$. Then, by Lemma B1, all committee members that are either to the right or to the left of the median, $m$, also accept $x$. Therefore, since $m$ is the median, the proposal is passed. The "only if" part is equally straightforward. By contradiction, suppose that the majority of members that accept a proposal does not include the median. This clearly contradicts Lemma B1.

Since the chairman only needs the approval of the median to pass a proposal and the preferences of the other members do not matter, then a committee with $n+1$ members is equivalent to a two-person committee with the chairman and the median as the only policy makers. 


\section{Algorithm to Solve for Stationary Decision Rules}

Step 1. Starting at time $t=\tau$, solve the chairman's optimization problem for a set of discrete nodes $n_{j}$, for $j=1,2, \ldots, N$ in $[0,1]$, given the shock $\varepsilon_{t}=\varepsilon^{i}$, for $i=1,2$. The nodes $n_{j}$ may be interpreted as possible status quo at the beginning of period $\tau$. Given $n_{j}$ and $\varepsilon^{i}$, the chairman's problem at time $t=\tau$ is

$$
V_{C, \tau}\left(n_{j}, \varepsilon^{i}\right)=\max _{x_{t} \in[0,1]} U_{C}\left(x_{t}, \varepsilon^{i}\right),
$$

subject to the nonlinear constraint $U_{P}\left(x_{t}, \varepsilon^{i}\right) \geq U_{P}\left(n_{j}, \varepsilon^{i}\right)$. This maximization problem is solved numerically for each $n_{j}$ and $\varepsilon^{i}$ using a hill-climbing method. The result is a collection of $2 N$ optimal proposal values $G_{C, \tau}\left(n_{j}, \varepsilon^{i}\right)$. Using these optimal values, compute $V_{C, \tau}\left(n_{j}, \varepsilon^{i}\right)=U_{C}\left(G_{C, \tau}\left(n_{j}, \varepsilon^{i}\right), \varepsilon^{i}\right)$ and $V_{P, \tau}\left(n_{j}, \varepsilon^{i}\right)=U_{P}\left(G_{C, \tau}\left(n_{j}, \varepsilon^{i}\right), \varepsilon^{i}\right)$ for all $n_{j}$ and $\varepsilon^{i}$.

Step 2. For each $\varepsilon^{i}$, approximate the continuous value function $V_{C, \tau}\left(q, \varepsilon^{i}\right)$ using a Chebyshev polynomial of order $N-1$. The polynomial coefficients are obtained from the Least Squares projection of $V_{C, \tau}\left(n_{j}, \varepsilon^{i}\right)$ on a constant and the first $N-1$ members of the Chebyshev polynomial family. At the $N$ nodes $q=n_{j}$, the Chebyshev polynomial fits $V_{C, \tau}\left(q, \varepsilon^{i}\right)$ exactly. For points $q \neq n_{j}$, the value of $V_{C, \tau}\left(q, \varepsilon^{i}\right)$ is computed by interpolation (i.e, by evaluating the Chebyshev polynomial at $q)$. For each $\varepsilon^{i}$, the value function $V_{P, \tau}\left(q, \varepsilon^{i}\right)$ is approximated likewise.

Step 3. Move backwards one period. For each possible status quo $n_{j}$ and each possible shock realization $\varepsilon^{i}$, solve numerically the chairman's problem

$$
V_{C, t}\left(n_{j}, \varepsilon^{i}\right)=\max _{x_{t} \in[0,1]} U_{C}\left(x_{t}, \varepsilon^{i}\right)+\delta \sum_{k=1}^{2} p_{k i} V_{C, t+1}\left(x_{t}, \varepsilon^{k}\right),
$$

subject to

$$
U_{P}\left(x_{t}, \varepsilon^{i}\right)+\delta \sum_{k=1}^{2} p_{k i} V_{P, t+1}\left(x_{t}, \varepsilon^{k}\right) \geq U_{P}\left(n_{j}, \varepsilon^{i}\right)+\delta \sum_{k=1}^{2} p_{k i} V_{C, t+1}\left(n_{j}, \varepsilon^{k}\right),
$$

where the value functions are replaced by their respective approximating polynomials. The result is a collection of $2 N$ optimal proposal values $G_{C, t}\left(n_{j}, \varepsilon^{i}\right)$. Using these optimal values, compute $V_{C, t}\left(n_{j}, \varepsilon^{i}\right)$ and $V_{P, t}\left(n_{j}, \varepsilon^{i}\right)$ for all $n_{j}$ and $\varepsilon^{i}$.

Step 4. Repeat Steps 2 and 3 backwards until the chairman's decision rules converge. 


\section{Committee with Staggered Terms}

Consider an infinite-horizon economy where the value of the policy instrument is selected by a two-person committee with finite and staggered terms. Under the assumptions spelled out below, it is possible to obtain an analytical solution for the stationary decision rules. Assume that the mandate of each member is two periods and it is not renewable. Committee members are labeled as junior (senior) in the first (second) period of their mandate. The senior member is assumed to be the chairman and, as in the model in the text, makes a take-it-or-leave-it offer to the junior member. Members can be of two types: hawks or doves, denoted by $\mathrm{H}$ and $\mathrm{D}$, respectively. The period utility of member $j=H, D$ is

$$
U_{j}\left(x_{t}, \varepsilon_{t}\right)=-\left(x_{t}-r_{j}\left(\varepsilon_{t}\right)\right)^{2},
$$

where $r_{j}\left(\varepsilon_{t}\right)$ denotes the preferred interest rate of individual $j$. Assume that the committee always includes a member $\mathrm{H}$ and a member $\mathrm{D}$. As before, there are two possible states of the world: a state of agreement and a state of disagreement. When $\varepsilon_{t}=\varepsilon^{2}$, both members agree that $1 / 2$ is the optimal policy. When $\varepsilon_{t}=\varepsilon^{1}$, agents $H$ and $D$ disagree in their preferred instrument values with $r_{H}\left(\varepsilon^{1}\right)=1$ and $r_{D}\left(\varepsilon^{1}\right)=0$. At the end of the mandate, each member is replaced by an individual with the same preferences. At the initial time $t=1$, the committee is composed of a junior dove and a senior hawk. At time $t=2$, the committee includes a junior hawk and a senior dove; and so on. Denote by $x^{H}$ the proposal that a senior hawk would make to a junior dove and by $x^{D}$ the proposal that a senior dove would make to a junior hawk.

Note that the senior chooses the policy that maximizes his period utility because he does not care about the next voting outcome. On the contrary, the junior member makes his acceptance decision by taking into account its effect on the next voting outcome. The proposal rule $G^{H}\left(q_{t}, \varepsilon_{t}\right)$ of senior $\mathrm{H}$ solves the following problem:

$$
\max _{x^{H} \in[0,1]}-\left(x_{t}^{H}-r_{H}\left(\varepsilon_{t}\right)\right)^{2}
$$

subject to

$-\left(x_{t}^{H}-r_{D}\left(\varepsilon_{t}\right)\right)^{2}-\delta E_{t}\left(G^{D}\left(x^{H}, \varepsilon_{t+1}\right)-r_{D}\left(\varepsilon_{t+1}\right)\right)^{2} \geq-\left(q_{t}-r_{D}\left(\varepsilon_{t}\right)\right)^{2}-\delta E_{t}\left(G^{D}\left(q_{t}, \varepsilon_{t+1}\right)-r_{D}\left(\varepsilon_{t+1}\right)\right)^{2}$.

Proposition $\mathrm{C} 1$ characterizes the equilibrium proposal rules.

Proposition C1: For all $q_{t} \in[0,1]$ the stationary proposal rules when $\varepsilon^{1}$ and $\varepsilon^{2}$ occur are, respectively, $G^{H}\left(q_{t}, \varepsilon^{1}\right)=G^{D}\left(q_{t}, \varepsilon^{1}\right)=q$ and

$G^{H}\left(q_{t}, \varepsilon^{2}\right)=\left\{\begin{array}{ll}1 / 2, & \text { for } q_{t} \in[0,2 z-1 / 2] \cup[1 / 2,1], \text { where } z=(1 / 2) /\left(1+\delta p_{12}\right), \\ 2 z-q_{t}, & \text { for } q_{t} \in(2 z-1 / 2, z), \\ q, & \text { for } q_{t} \in[z, 1 / 2] .\end{array}\right.$, 


$$
G^{D}\left(q_{t}, \varepsilon^{2}\right)= \begin{cases}1 / 2, & \text { for } q_{t} \in[0,1 / 2] \cup\left[2 y-q_{t}, 1\right], \text { where } y=\left(1 / 2+\delta p_{12}\right) /\left(1+\delta p_{12}\right), \\ q_{t}, & \text { for } q_{t} \in(1 / 2, y), \\ 2 y-q_{t}, & \text { for } q_{t} \in\left[y, 2 y-q_{t}\right] .\end{cases}
$$

Proof: When $\varepsilon^{1}$ occurs, the period utility of senior $H$ is increasing in $x^{H}$ and has a peak at 1. Taking as given the posited policy rules at period $t+1$, the expected two-period utility of the junior $D$ is

$$
E_{t} u_{D}\left(x^{H}, \varepsilon^{1}\right)=-\left(x_{t}^{H}\right)^{2}-\delta p_{21}\left(G^{D}\left(x_{t}^{H}, \varepsilon^{2}\right)-\frac{1}{2}\right)^{2}-\delta p_{11}\left(x^{H}\right)^{2} .
$$

Note that because of the non-monotonicity of $G^{D}\left(x^{H}, \varepsilon^{2}\right)$, the second term is non-monotone in $x^{H}$, while the first and the third term are decreasing in $x^{H}$. Overall, one can verify that the expected life-time utility of junior $\mathrm{D}$ decreases in $x^{H}$. This implies that the best acceptable proposal for senior $H$ is the status quo. This proves that $G^{H}\left(q_{t}, \varepsilon^{1}\right)=q_{t}$. When $\varepsilon^{2}$ occurs, the utility of the senior $\mathrm{H}$ is symmetric and has a peak at $1 / 2$. The expected two-period utility of the junior $\mathrm{D}$ is

$$
E u_{D}\left(x^{H}, \varepsilon^{2}\right)=-\left(x^{H}-\frac{1}{2}\right)^{2}-\delta p_{22}\left(G^{D}\left(x^{H}, \varepsilon^{2}\right)-\frac{1}{2}\right)^{2}-\delta p_{12}\left(x^{H}\right)^{2} .
$$

One can verify that $E u_{D}\left(x^{H}, \varepsilon^{2}\right)$ has a single peak in $(1 / 2) /\left(1+\delta p_{12}\right)$ and it is symmetric in the interval $[0,1 / 2]$. This implies that the chairman is able to propose his ideal point $1 / 2$ whenever $q_{t} \in[0,2 z-1 / 2] \cup[1 / 2,1]$ but can only propose the status quo when $q_{t} \in[z, 1 / 2]$. Thus, $[z, 1 / 2]$ is a gridlock interval. Proving that the posited proposal rule $G^{D}\left(q_{t}, \varepsilon_{t}\right)$ is an equilibrium strategy follows a parallel argument. 


\section{References}

[1] Alesina, Alberto, (1987), "Macroeconomic Policy in a Two-Party System as a Repeated Game," Quarterly Journal of Economics 102, pp. 651-678.

[2] Baron, David P., (1996), "A Dynamic Theory of Collective Goods Programs," American Political Science Review 90, pp. 316-330.

[3] Baron, David P. and Eheud Kalai, (1993), "The Simplest Equilibrium of a Majority Rule Game," Journal of Economic Theory 61, pp. 290-301.

[4] Baron, David P. and John Ferejohn, (1989), "Bargaining in Legislatures," American Political Science Review 83, pp. 1181-1206.

[5] Baron, David P. and Michael C. Herron, (2003). "A Dynamic Model of Multidimensional Collective Choice" in Computational Models in Political Economy, Ken Kollman, John H. Miller, and Scott E. Page, eds. Cambridge, MA: The MIT Press.

[6] Belden, Susan, (1989), "Policy Preferences of FOMC Members as Revealed by Dissenting Votes," Journal of Money, Credit and Banking 21, pp. 432-441.

[7] Bernheim, Douglas, Antonio Rangel and Luis Rayo, (2006), "The Power of the Last Word in Legislative Policy Making." Econometrica 74, pp. 1161-1190.

[8] Besley, Timothy and Stephen Coate, (1998). "Sources of Inefficiency in a Representative Democracy: A Dynamic Analysis," American Economic Review 88, 139-156.

[9] Blinder, Alan S., (2004), The Quiet Revolution: Central Banking Goes Modern, New Haven: Yale University Press.

[10] Blinder, Alan S. and John Morgan, (2005), "Are Two Heads Better Than One? Monetary Policy by Committee," Journal of Money, Credit and Banking 37, pp. 789-812.

[11] Blinder, Alan S., (2007), "Monetary Policy by Committee: Why and How?" European Journal of Political Economy 23, pp. 106-123.

[12] Bullard, James and Christopher Waller, (2004), "Central Bank Design in General Equilibrium," Journal of Money, Credit and Banking 36, pp. 95-113.

[13] Clarida, Richard, Jordi Gali and Mark Gertler, (1999), "The Science of Monetary Policy: A New Keynesian Perspective," Journal of Economic Literature 37, pp. 1661-1707. 
[14] Clarida, Richard, Jordi Gali and Mark Gertler, (2000), "Monetary Policy Rules and Macroeconomic Stability: Evidence and Some Theory," Quarterly Journal of Economics 115, pp. $147-180$.

[15] Chappell, Henry W., Rob Roy McGregor, and Todd Vermilyea, (2005), Committee Decisions on Monetary Policy, Cambridge, MA: The MIT Press.

[16] Cukierman, Alex, (1991), "Why Does the Fed Smooth Interest Rates?" in Monetary Policy on the 75th Anniversary of the Federal Reserve System, Michael Belongia, ed., Boston: Kluwer Academic Publishers, pp. 111-47.

[17] Dal Bó, Ernesto, (2006), "Committees With Supermajority Voting Yield Commitment With Flexibility," Journal of Public Economics 90, pp. 573-599.

[18] English, William, William Nelson, and Brian Sack, (2003), "Interpreting the Significance of the Lagged Interest Rate in Estimated Monetary Policy Rules," Contributions to Macroeconomics 3(1), Article 5.

[19] Eijffinger, Sylvester, Eric Schaling, and Willem Verhagen, (1999), "A Theory of Interest Rate Stepping: Inflation Targeting in a Dynamic Menu Cost Model," Tilburg University, Mimeo.

[20] Fong, Pohan, (2006), "Dynamics of Government and Policy Choice," Concordia University, Mimeo.

[21] Fry, Maxwell, DeAnne Julius, Lavan Mahadeva, Sandra Roger, and Gabriel Sterne, (2000), "Key Issues in the Choice of Monetary Policy Framework," in Monetary Frameworks in a Global Context, Lavan Mahadeva and Gabriel Sterne (eds.), London: Routledge.

[22] Gerlach-Kristen, Petra, (2006). "Monetary Policy Committees and Interest Rate Setting," European Economic Review 50, pp. 487-507.

[23] Gildea, John A., (1992), "The Regional Representation of Federal Reserve Bank Presidents," Journal of Money, Credit and Banking 24, pp. 215-225.

[24] Goodfriend, Marvin, (1991), "Interest Rate $x_{t}$ in the Conduct of Monetary Policy," Carnegie-Rochester Conference Series on Public Policy 37, pp. 7-30.

[25] Graeme, Guthrie and Julian Wright, (2004), "The Optimal Design of Interest Rate Target Changes," Journal of Money, Credit and Banking 36, pp. 115-137. 
[26] Havrilesky, Thomas M. and Robert L. Schweitzer, (1990), "A Theory of FOMC Dissent Voting with Evidence from the Time Series," in The Political Economy of American Monetary Policy, Thomas Mayer, ed., Cambridge: Cambridge University Press, pp. 197-210.

[27] Hetzel, Robert L., (1998), "Arthur Burns and Inflation," Federal Reserve Bank of Richmond Quarterly Review 84, pp. 21-44.

[28] Maier, Philipp, (2007), "Monetary Policy Committees in Action: Is There Room for Improvement?" Bank of Canada Working Paper 2007-6.

[29] Maisel, Sherman, (1973), Managing the Dollar, New York: W. W. Norton and Company.

[30] Meade, Ellen and Nathan Sheets, (2005) "Regional Influences on FOMC Voting Patterns," Journal of Money, Credit, and Banking, 37, p. 661-677.

[31] Meyer, Laurence H., (2004), A Term at the Fed, New York: Harper Collins.

[32] Lombardelli, Clare, James Proudman, and James Talbot, (2005), "Committee Versus Individuals: An Experimental Analysis of Monetary Policy Decision Making," International Journal of Central Banking 1, pp. 181-205.

[33] Orphanides, Athanasios, (2003), "Monetary Policy Evaluation with Noisy Information," Journal of Monetary Economics 50, pp. 605-31.

[34] Rasch, Bjorn Eric, (2000), "Parliamentary Floor Procedures and Agenda Setting in Europe," Legislative Studies Quarterly 25, pp. 3-23.

[35] Riboni, Alessandro, (2004), "Committees as Substitute for Commitment," University of Montreal, Mimeo.

[36] Riboni, Alessandro, and Francisco Ruge-Murcia, (2007a), "Preference Heterogeneity in Monetary Policy Committees," International Journal of Central Banking, forthcoming.

[37] Riboni, Alessandro, and Francisco Ruge-Murcia, (2007b), "Monetary Policy by Committee: Consensus, Chairman Dominance or Simple Majority?" University of Montreal, Mimeo. Paper presented at the Workshop on Monetary Policy Committees organized by the Norges Bank, September 2007.

[38] Romer, Christina and David Romer, (2004), "Choosing the Federal Reserve Chair: Lessons from History," Journal of Economic Perspectives 18, p.129-162. 
[39] Romer, Thomas and Howard Rosenthal, (1978), "Political Resource Allocation, Controlled Agendas, and the Status Quo," Public Choice 33, pp. 27-44.

[40] Samuelson, William and Richard, Zeckhauser, (1988), "Status Quo Bias in Decision Making," Journal of Risk and Uncertainty 1, pp. 7-59.

[41] Sibert, Anne, (2003) "Monetary Policy Committees: Individual and Collective Reputations," Review of Economic Studies 70, pp. 649-665.

[42] Tsebelis, George, (2002), Veto Players: How Political Institutions Work, Princeton: Princeton University Press.

[43] Judd, Kenneth L., (1998), Numerical Methods in Economics, Cambridge: MIT Press.

[44] Waller, Christopher J., (2000), "Policy Boards and Policy $x_{t}$," Quarterly Journal of Economics 115, pp. 305-339.

[45] Waller, Christopher J., (1992) "A Bargaining Model of Partisan Appointments to the Central Bank" Journal of Monetary Economics 29: 411-428.

[46] Waller, Christopher J. and Carl E. Walsh, (1996) "Central Bank Independence, Economic Behavior and Optimal Term Lengths," American Economic Review, 86 (5), Dec. 1996, 1139-1153.

[47] Woodford, Michael, (2003), "Optimal Interest-Rate $x_{t}$, " Review of Economic Studies 70, pp. 861-886. 
Figure 1: Policy Rules for Two-State Model
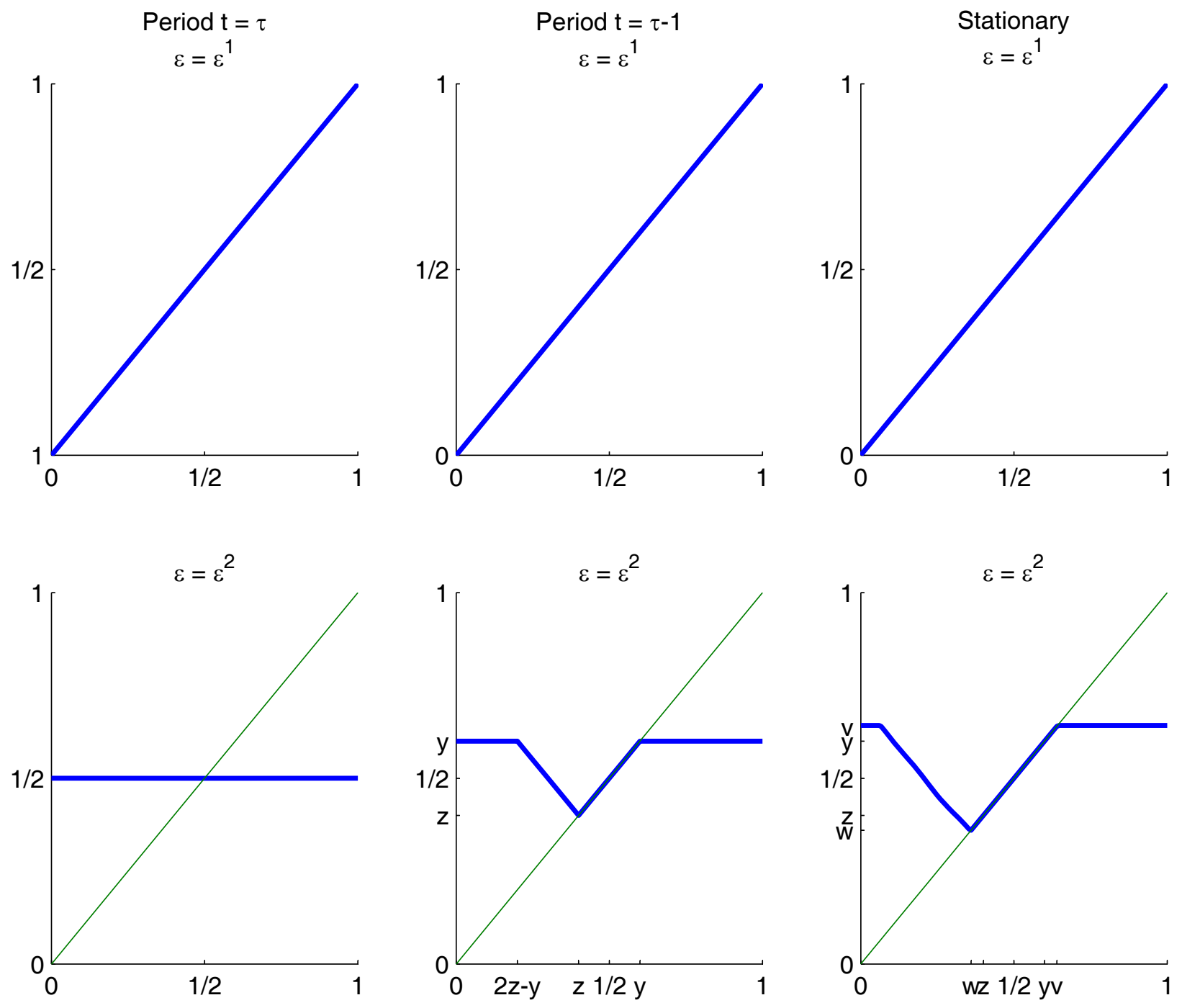
Figure 2: Policy Rules for Six-State Model
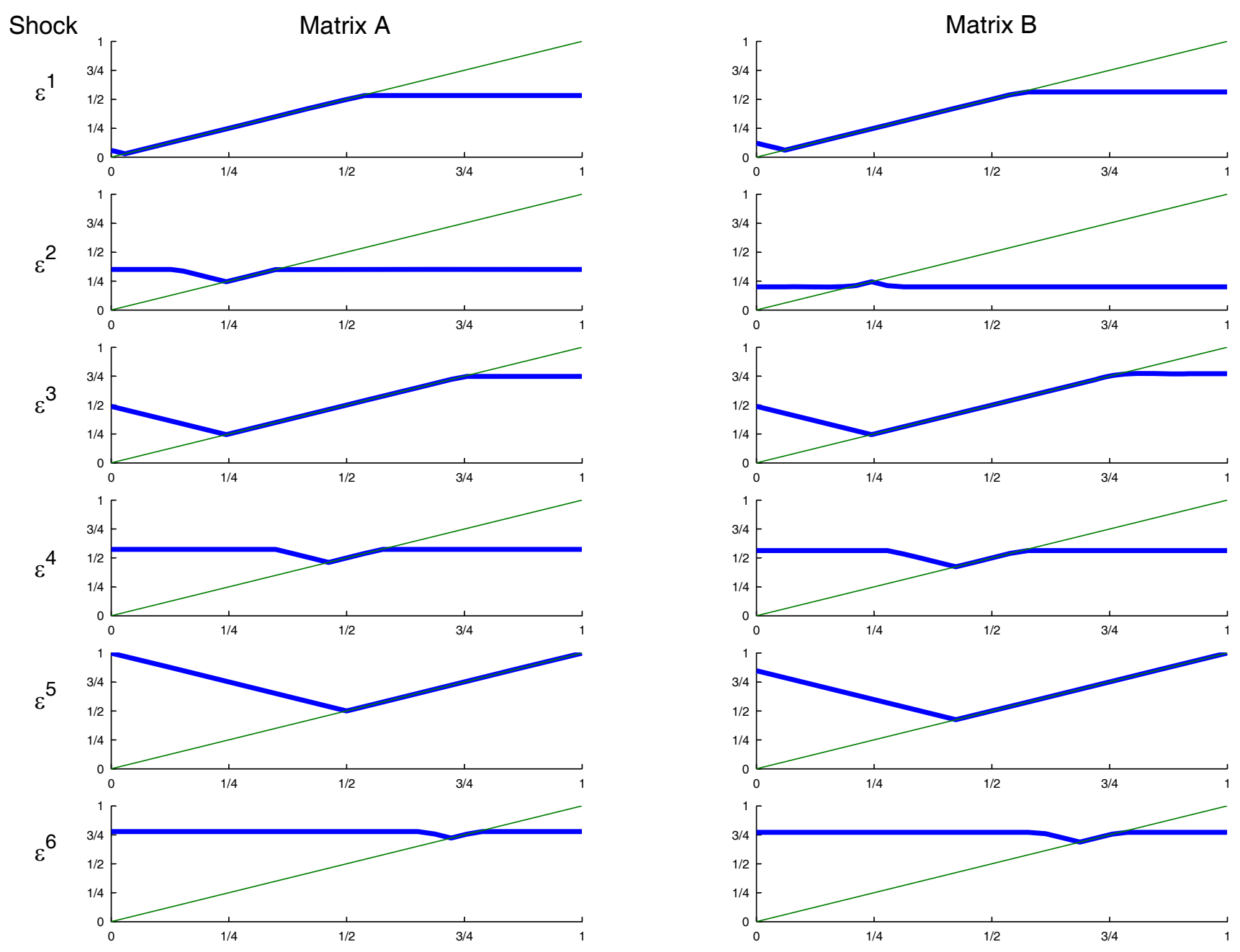
Figure 3: Simulations
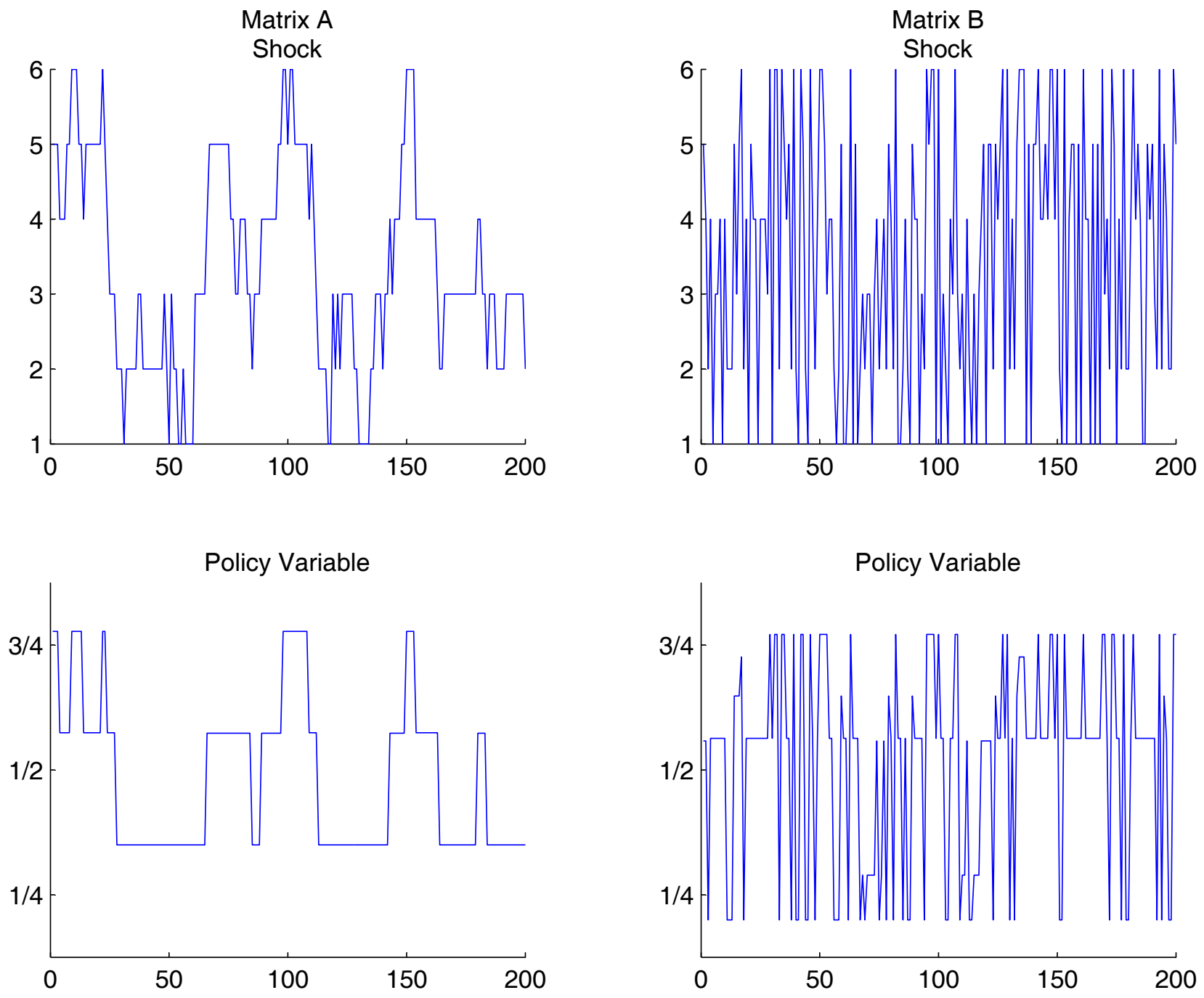
Figure 4: Histograms
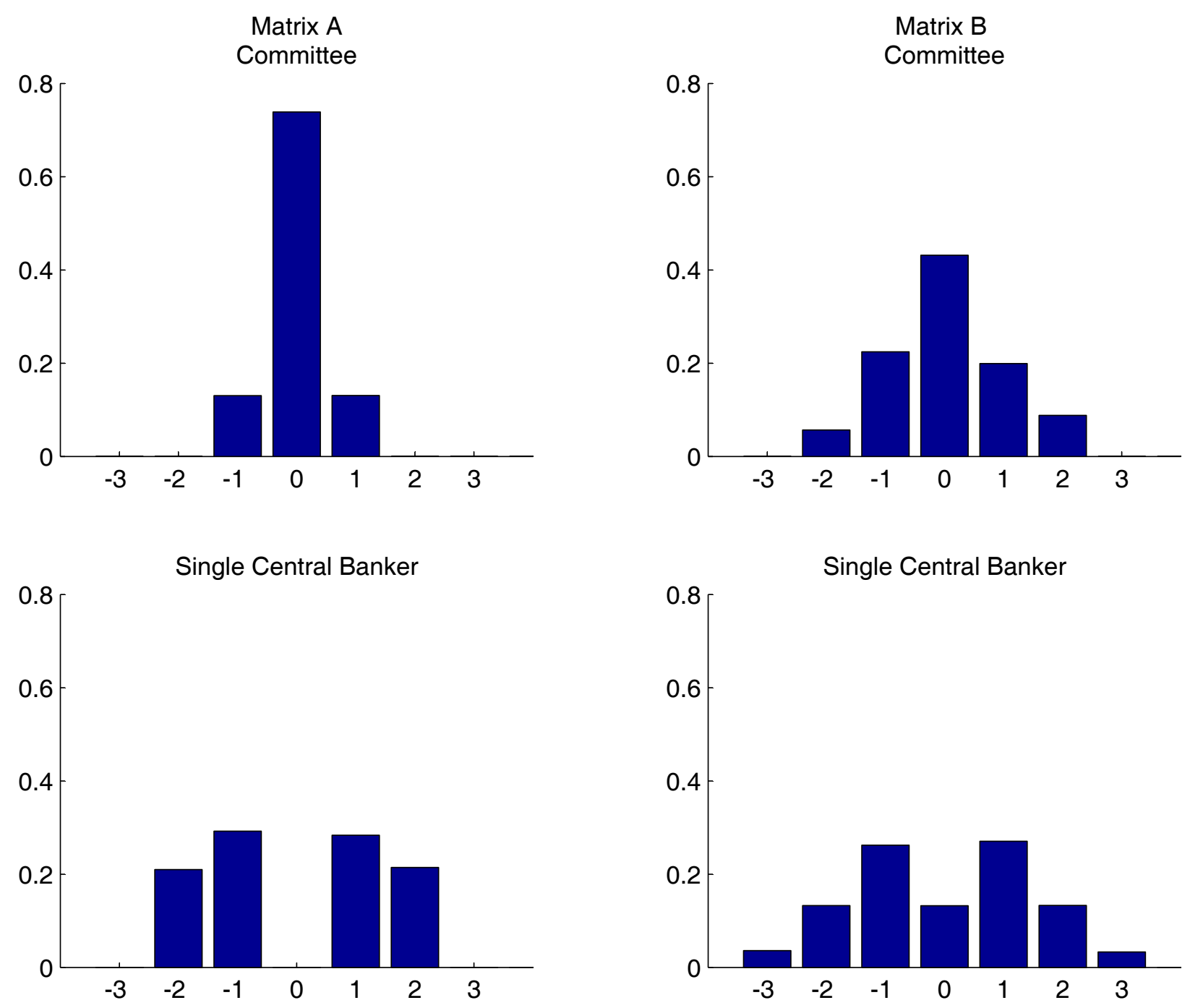
Figure 5: Monetary Policy Decisions
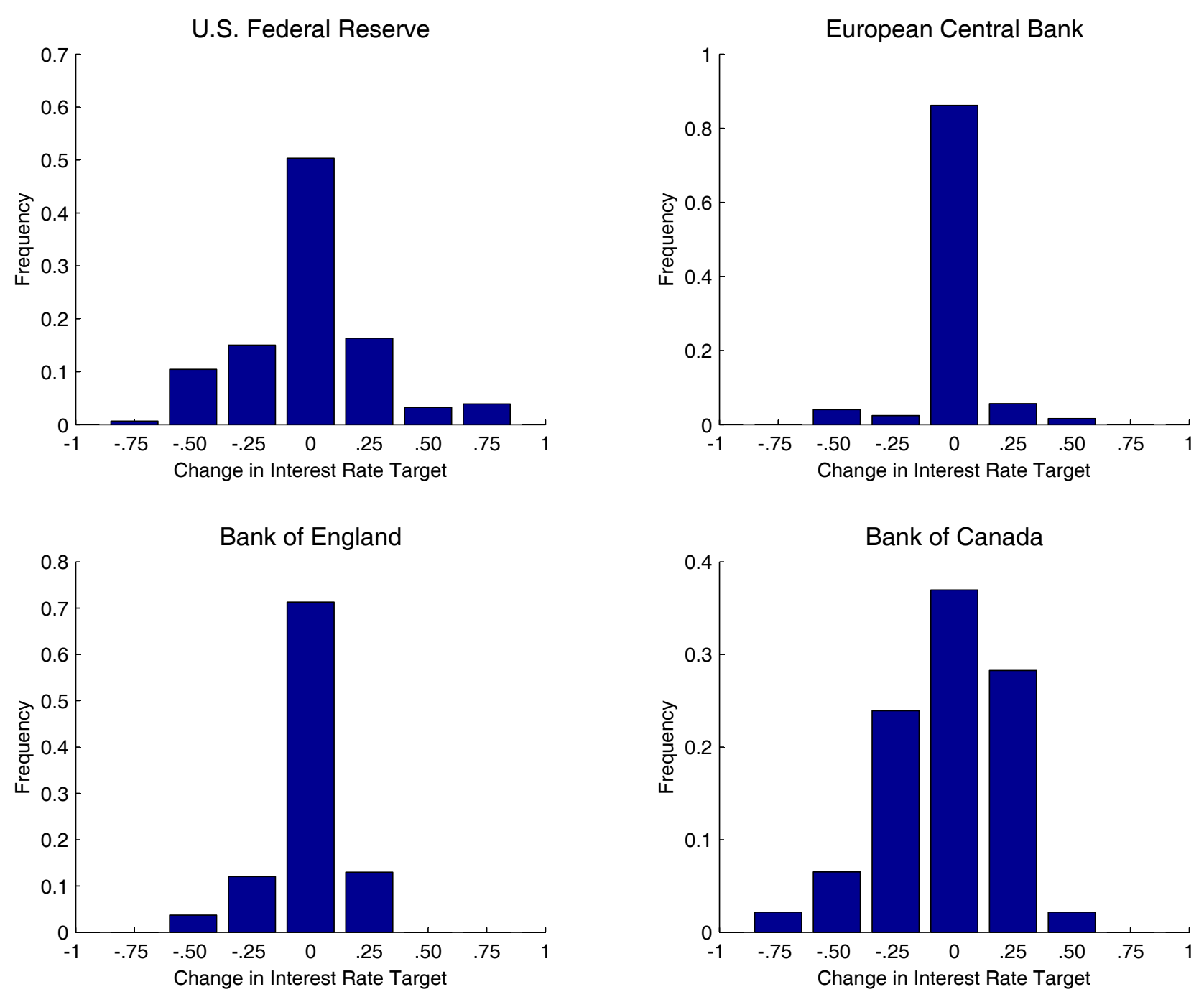
Figure 6: Autocorrelation Functions
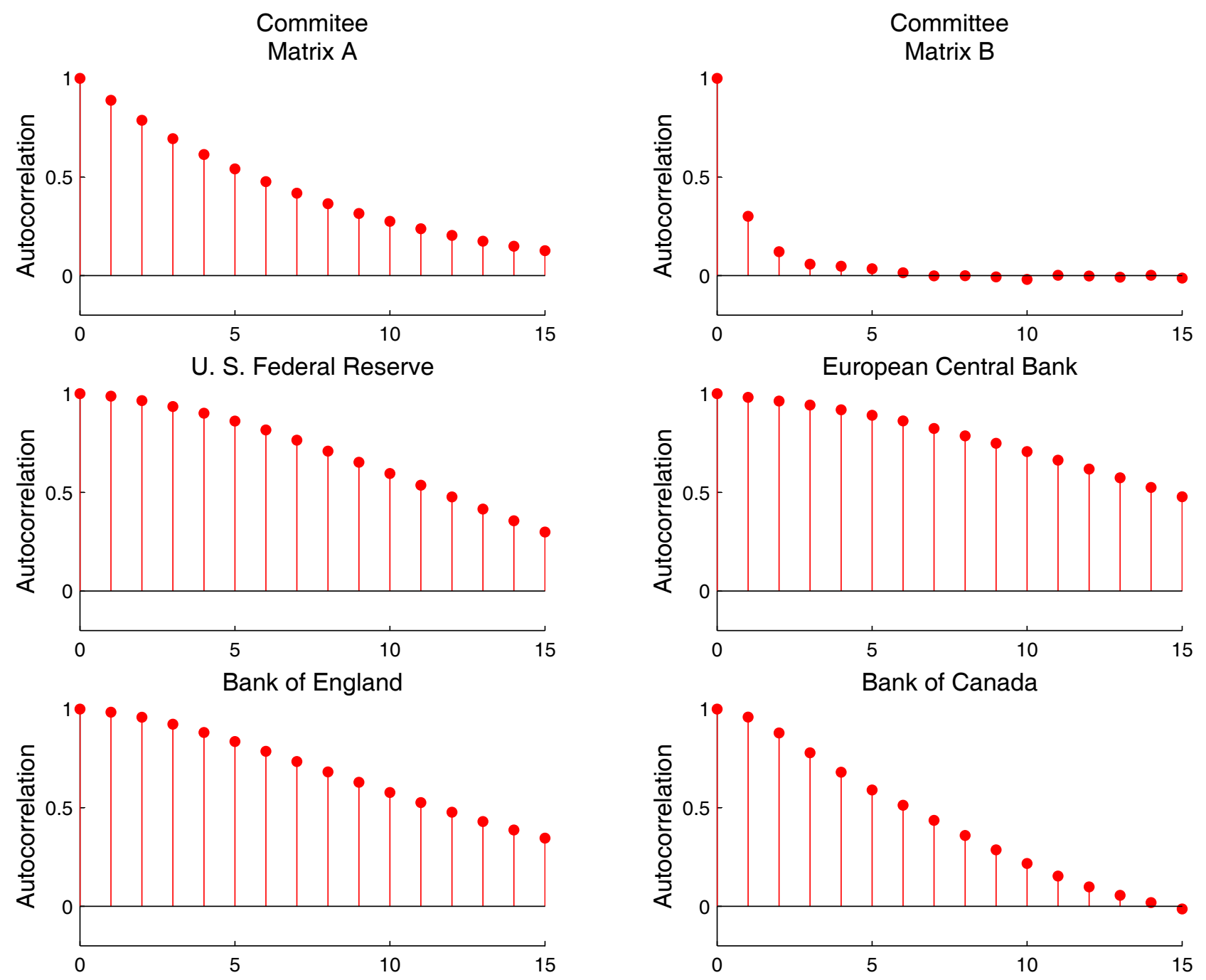
Figure 7: Stationary Policy Rules when Default is Fixed
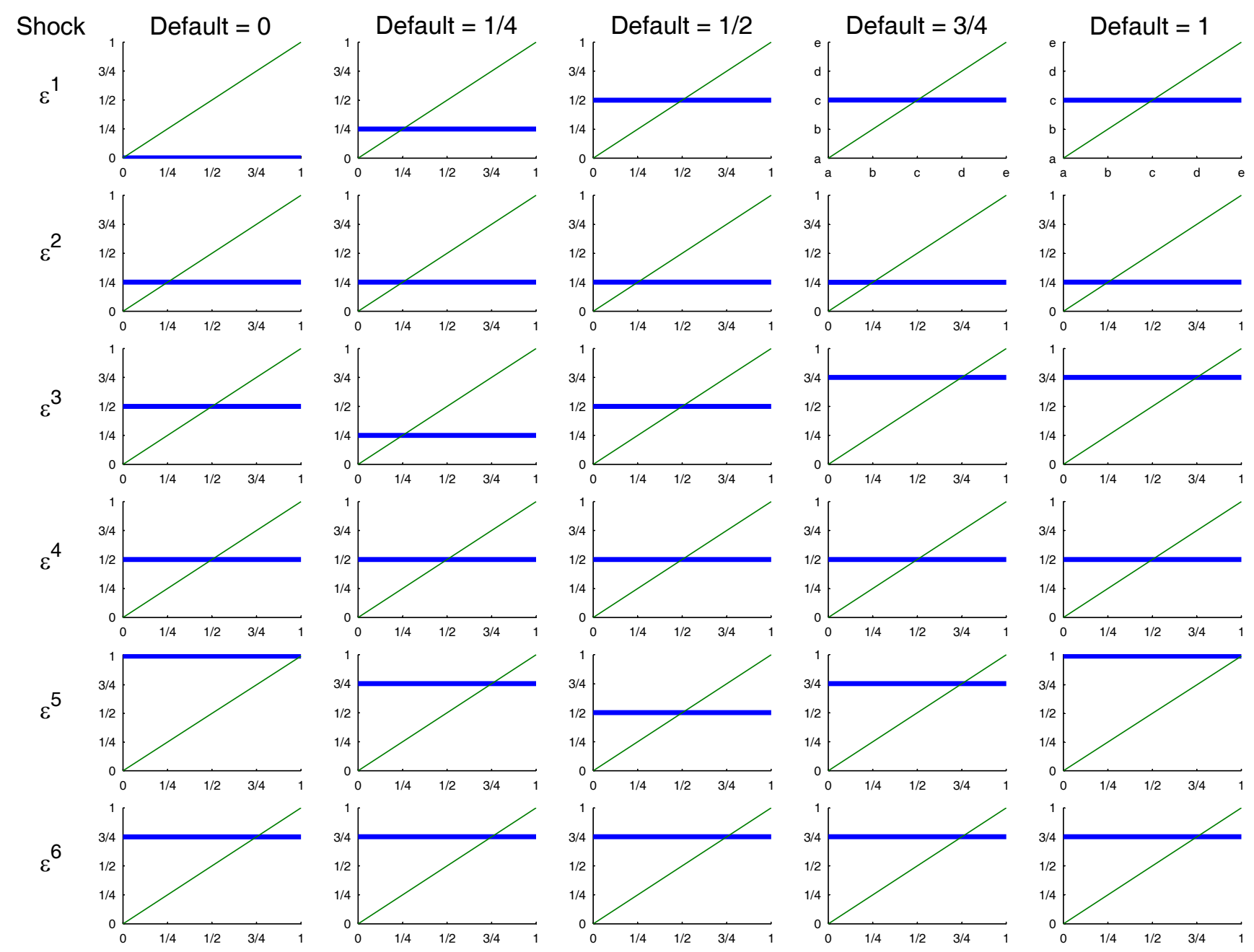